\title{
CD47: A Cell Surface Glycoprotein Which Regulates Multiple Functions of Hematopoietic Cells in Health and Disease
}

\author{
Per-Arne Oldenborg \\ Section for Histology and Cell Biology, Department of Integrative Medical Biology, Umeå University, 90187 Umeå, Sweden \\ Correspondence should be addressed to Per-Arne Oldenborg; per-arne.oldenborg@histocel.umu.se
}

Received 31 October 2012; Accepted 19 November 2012

Academic Editors: L. Bordin, K. Oritani, F. W. Quelle, K. Suzukawa, and K.-F. Wong

Copyright (C) 2013 Per-Arne Oldenborg. This is an open access article distributed under the Creative Commons Attribution License, which permits unrestricted use, distribution, and reproduction in any medium, provided the original work is properly cited.

\begin{abstract}
Interactions between cells and their surroundings are important for proper function and homeostasis in a multicellular organism. These interactions can either be established between the cells and molecules in their extracellular milieu, but also involve interactions between cells. In all these situations, proteins in the plasma membranes are critically involved to relay information obtained from the exterior of the cell. The cell surface glycoprotein CD47 (integrin-associated protein (IAP)) was first identified as an important regulator of integrin function, but later also was shown to function in ways that do not necessarily involve integrins. Ligation of CD47 can induce intracellular signaling resulting in cell activation or cell death depending on the exact context. By binding to another cell surface glycoprotein, signal regulatory protein alpha (SIRP $\alpha$ ), CD47 can regulate the function of cells in the monocyte/macrophage lineage. In this spotlight paper, several functions of CD47 will be reviewed, although some functions may be more briefly mentioned. Focus will be on the ways CD47 regulates hematopoietic cells and functions such as CD47 signaling, induction of apoptosis, and regulation of phagocytosis or cell-cell fusion.
\end{abstract}

\section{Structure and Expression of CD47 in the Plasma Membrane}

CD47 (originally named integrin-associated protein (IAP)) is a cell surface protein of the immunoglobulin (Ig) superfamily, which is heavily glycosylated and expressed by virtually all cells in the body [1]. CD47 was first recognized as a $50 \mathrm{kDa}$ protein associated and copurified with the $\alpha_{\mathrm{v}} \beta_{3}$ integrin in placenta and neutrophil granulocytes and later shown to have the capacity to regulate integrin function and the responsiveness of leukocytes to RGD-containing extracellular matrix proteins [1-4]. Soon after this integrin-associated protein was cloned, it was shown to be identical to the erythrocyte cell surface antigen CD47 [5]. The fact that CD47 is also expressed by cells like erythrocytes, that do not express integrins, indicates that it can be more appropriate to refer to this protein as CD47 than using its original name integrin-associated protein (IAP). The protein is fairly well conserved between species and has about $60-70 \%$ similarity in the amino acid sequence when comparing human CD47 with that of mouse, rat, and bovine CD47. CD47 has also been shown to be identical to the OA-3/OVTL3 antigen highly expressed on most ovarian carcinomas $[6,7]$. It also shows homology to a protein family of variola and vaccinia viruses $[1,5,6]$, the significance of which is still unclear. CD47 consists of an extracellular IgV domain, a five times transmembrane-spanning domain, and a short alternatively spliced cytoplasmic tail. In both humans and mice, the cytoplasmic tail can be found as four different splice isoforms ranging from 4 to 36 amino acids, showing different tissue expression patterns. The 16 amino acid form 2 , which is by far the predominant isoform, is expressed in all cells of hematopoietic origin, as well as in endothelial and epithelial cells [8]. In contrast, the 36 amino acid form 4 is expressed primarily in neurons, intestine, and testis [8]. Expression of the 4 amino acid form 1 is found in epithelial and endothelial cells, while the expression pattern of the 23 amino acid form 3 resembles that of form 4 [8]. Despite a study showing that CD47 form 3 and 4 could be associated with memory retention in rats, and that form 2 is predominating in astrocytes [9], little is known as to what these splice variants mean in terms of possible difference in the functionality of the protein. A new twist in the understanding of CD47 comes from a recent finding that CD47 can be expressed as a proteoglycan with a molecular weight 
of $>250 \mathrm{kDa}$, having both heparin and chondroitin sulfate glycosaminoglycan (GAG) chains [10]. This form of CD47 was found to be expressed in both the human Jurkat $\mathrm{T}$ cell line and in murine primary $\mathrm{T}$ cells, as well as in human umbilical vein endothelial cells (HUVECs), murine lung endothelial cells, and in human smooth muscle cells [10]. Functionally, the GAG chains at CD47 Ser ${ }^{64}$ were found to be crucial to inhibit $\mathrm{T}$ cell receptor signaling following the ligation of CD47 by its ligand thrombospondin-1 [10].

\section{Intracellular Signaling following CD47 Interactions with Integrins, Thrombospondin (TSP), or Signal Regulatory Proteins (SIRPs)}

2.1. Interaction with Integrins. Early studies of CD47 were based on the use of monoclonal antibodies (mAbs) raised against the CD47 protein purified from placenta $[2,11]$, showing a role of CD47 in mediating an enhanced IgGmediated phagocytosis response in the presence of RGDcontaining ligands, such as fibronectin, fibrinogen, vitronectin, or collagen type IV $[2,11]$. The same mAbs were also found to block neutrophil transendothelial migration stimulated by interleukin 8 (IL-8) or the bacterial peptide $\mathrm{N}$-formyl-methionyl-leucyl-phenylalanine (f-Met-Leu-Phe) and to inhibit neutrophil migration across tumor-necrosisfactor- $\alpha$ - (TNF $\alpha-)$ stimulated endothelial cells, where CD47 on both the neutrophils and the endothelial cells was found to be important [12]. Generation of other anti-CD47mAbs, raised against epithelial membrane preparations, showed that CD47 is present at the basolateral membrane of epithelial cell monolayers, that mAbs blocking CD47 on either neutrophils or the epithelial cells delay neutrophil transepithelial migration [13], and that efficient neutrophil chemotaxis correlates with an increased neutrophil cell surface expression of CD47 [14]. The basement membrane protein entactin, which contains an RGD sequence, was also found to stimulate neutrophil adhesion and chemotaxis in a CD47-dependent manner in vitro [15]. Generation of CD47-deficient mice further proved the importance of this protein in regulating neutrophil inflammatory responses, by showing an increased sensitivity to bacterial infection due to a delayed neutrophil accumulation in bacterial peritonitis [4]. CD47-deficient neutrophils also show a strongly impaired RGD-stimulated neutrophil adhesion, phagocytosis, and respiratory burst [4]. For $\alpha_{\mathrm{v}} \beta_{3}$ integrin-mediated cellular responses to the extracellular matrix protein vitronectin, CD47 was found to be required for $\alpha_{\mathrm{v}} \beta_{3}$-mediated binding to vitronectin-coated beads, but not $\alpha_{\mathrm{v}} \beta_{3}$-mediated adhesion to vitronectin-coated surfaces [3]. In addition to its original association with $\alpha_{\mathrm{v}} \beta_{3}$ integrins, CD47 has also been shown to interact with and regulate the integrins $\alpha_{2} \beta_{1}$ and $\alpha \mathrm{II}_{\mathrm{b}} \beta_{3}$ on platelets $[16,17]$, the $\alpha_{2} \beta_{1}$ integrin on smooth muscle cells [18], the $\alpha_{4} \beta_{1}$ integrin on sickle red blood cells and $\mathrm{B}$ lymphocytes $[19,20]$, the $\alpha_{6} \beta_{1}$ integrin in microglia [21], and the $\alpha_{5}$ integrin in chondrocytes [22] (Figure 1).
2.2. Interaction with Thrombospondin. Thrombospondin-1 (TSP-1) is the prototypic member of the thrombospondin family of extracellular matrix glycoproteins, which are implicated in regulating cell motility, proliferation, and differentiation [23]. The extracellular IgV domain of CD47 was found to be a receptor for the $\mathrm{C}$-terminal cell-binding domain (CBD) of TSP-1, since the expression of CD47 in otherwise CD47-deficient cells promotes adhesion to TSP-1 or its CBD, and a functional blocking $\mathrm{mAb}$ against CD47 can block endothelial cell chemotaxis against TSP-1 or the CD47 binding $\mathrm{CBD}$-peptide $4 \mathrm{~N} 1 \mathrm{~K}$ [24]. It was later shown that TSP1 , its $\mathrm{CBD}$, or the $4 \mathrm{~N} 1 \mathrm{~K}$ peptide stimulates $\alpha_{\mathrm{v}} \beta_{3}$ integrinmediated cell spreading on vitronectin in a CD47-dependent manner [24]. In platelets, TSP-1, the TSP-1 CBD, or $4 \mathrm{~N} 1 \mathrm{~K}$ activates the platelet $\alpha \mathrm{II}_{\mathrm{b}} \beta_{3}$ integrin and induces platelet spreading on fibrinogen, platelet aggregation, and increased focal adhesion kinase (FAK) tyrosine phosphorylation, which are all dependent on interaction between CD47 and integrin $\alpha \mathrm{II}_{\mathrm{b}} \beta_{3}$ [16]. Furthermore, CD47 was found to mediate a synergistic effect of soluble type I collagen and TSP- 1 or $4 \mathrm{~N} 1 \mathrm{~K}$, which enhance $\alpha_{2} \beta_{1}$ integrin-mediated platelet activation or vascular smooth muscle cell chemotaxis $[17,18]$. Early experiments also suggested that CD47 regulates TSP-1-induced cell spreading or platelet activation by affecting signal transduction in a pertussis toxin-sensitive way via a heterotrimeric Gi protein $[16,24]$. CD47 was later shown to functionally associate with heterotrimeric $\mathrm{Gi}$, to suppress cAMP levels, and mediate the inhibition of ERK in platelets and smooth muscle cells [25]. More recently, CD47 ligated by TSP-1 was found to inhibit nitric oxide (NO) signaling in vascular cells [26] and to oppose NO/cGMP-mediated inhibition of integrin activation to facilitate platelet aggregation [27].

In addition to signaling through $\mathrm{Gi}$ proteins, CD47 has been shown to signal via the $\beta_{3}$ integrin cytoplasmic tail [28]. Although it is not entirely clear how much these two signaling pathways overlap, accumulation of CD $47 / \beta_{3}$-integrincomplexes in cholesterol-rich lipid rafts, which appears to depend on both the CD47 IgV domain, the multiple transmembrane-spanning domain, and a long range disulfide bond between $\mathrm{Cys}^{33}$ in the $\mathrm{IgV}$ domain and $\mathrm{Cys}^{263}$ in the transmembrane domain [29], engage in Gi signaling [30]. CD47 has also been shown to be involved in the regulation of intracellular $\mathrm{Ca}^{2+}\left(\left[\mathrm{Ca}^{2+}\right]_{\mathrm{i}}\right)$, exemplified by its regulation of an integrin-dependent increase in $\left[\mathrm{Ca}^{2+}\right]_{\mathrm{i}}$ in endothelial cells [31] and tumor cells [32], and that CD47 synergizes with $\mathrm{T}$ cell receptor-stimulated elevations of $\left[\mathrm{Ca}^{2+}\right]_{\mathrm{i}}$ in $\mathrm{T}$ lymphocytes $[33,34]$. The cytoplasmic tails of the form 2 and form 4 splice variants of CD47 were found to bind to the cytosolic ubiquitin-related proteins PLIC-1 and PLIC2 (PLIC, proteins linking IAP to cytoskeleton) [35]. In B lymphocytes, CD47 was suggested to synergistically promote cell migration trough Cdc42 [20]. A role of Cdc42 and Rac has also been suggested in CD47-dependent regulation of neuronal development and neurite formation [36, 37]. Adhesion of intestinal epithelial cells to collagen I induces the association of CD47 with $\alpha_{2}$ integrins, and CD47 is necessary for collagen I-induced cyclooxygenase-2 (Cox-2) expression 


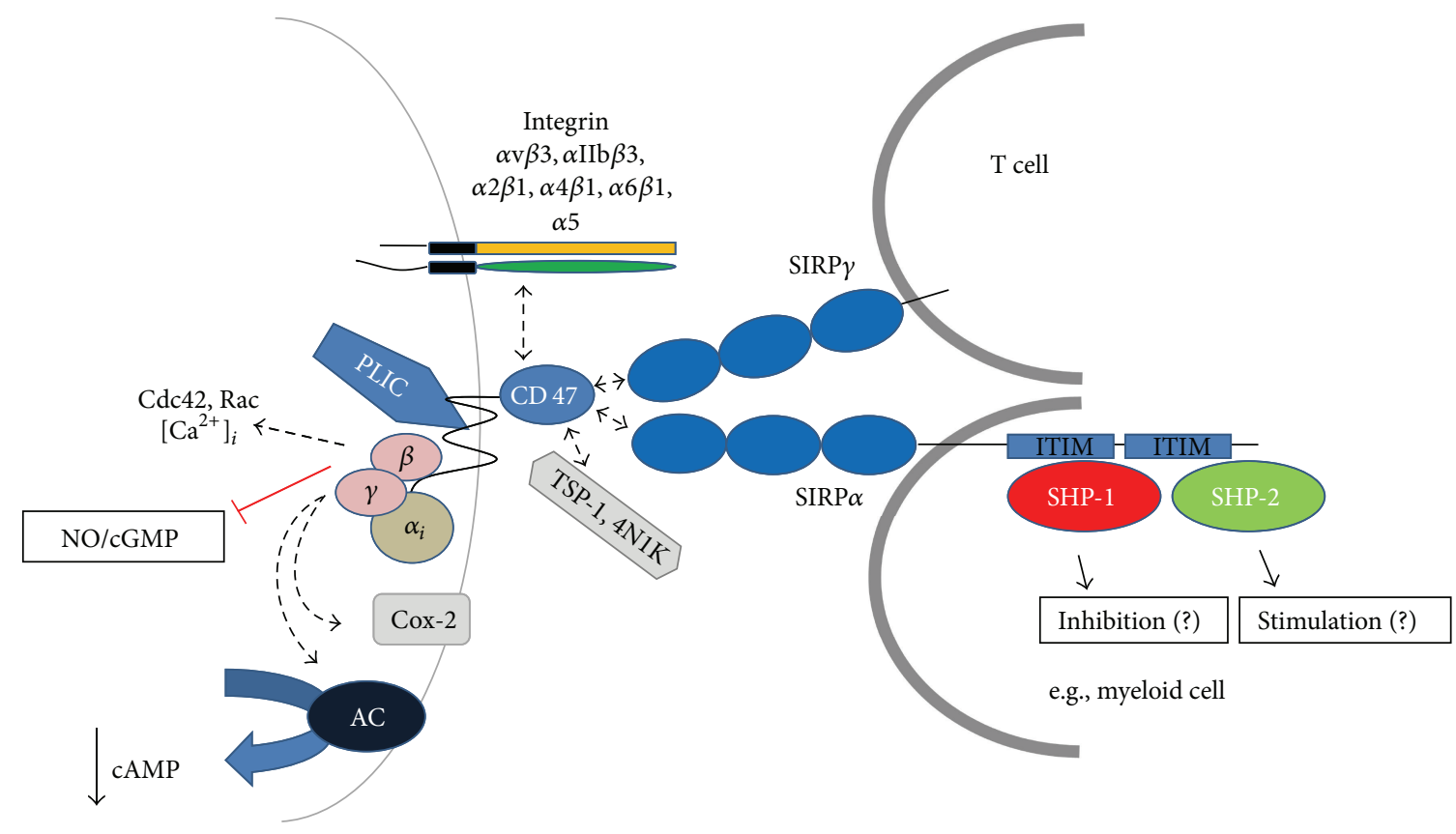

FIGURE 1: Interactions of CD47 in cis and trans. CD47 interacts in cis with integrins, in trans with SIRPs, and can also bind the soluble protein TSP-1. The figure summarizes intracellular signaling events associated with CD47 upon binding to its interaction partners.

and epithelial cell migration, which is mediated by $\mathrm{G} \alpha_{\mathrm{i} 3}$ [38] (Figure 1).

\subsection{Interaction with SIRP Proteins. SIRP proteins belong} to the Ig family of cell surface glycoproteins, where the first member identified was SIRP $\alpha$ (also known as SHPS-1, CD172a, BIT, MFR, or P84) [39-44]. SIRP $\alpha$ is highly expressed in myeloid cells and neurons, but also in endothelial cells and fibroblasts, and has three extracellular Ig-like domains, one distal IgV-like domain, and two membrane proximal IgC-like domains [41, 42]. In addition, an alternatively spliced form having only one $\operatorname{IgV}$ domain has also been reported [45]. In its intracellular tail, SIRP $\alpha$ has two immunoreceptor tyrosine-based inhibitory motifs (ITIMs), which when tyrosine phosphorylated can bind the Src homology 2 ( $\mathrm{SH} 2$ ) domain-containing protein-tyrosine phosphatases SHP-1 and SHP-2 [42]. Additional cytoplasmic binding partners for SIRP $\alpha$ are the adaptor molecules Src kinase-associated protein of $55 \mathrm{kDa}$ homolog/SKAP2 (SKAP55hom/R), Fyn-binding protein/SLP-76-associated phosphoprotein of $130 \mathrm{kDa}$ (FYB/SLAP-130), and the tyrosine kinase PYK2 [46]. SIRP $\alpha$ is also a substrate for the kinase activity of the insulin, EGF, and bPDGF receptors, and the overexpression of SIRP $\alpha$ in fibroblasts decreases proliferation and other downstream events in response to insulin, EGF, and bPDGF [42]. Since SIRP $\alpha$ is also constitutively associated with the M-CSF receptor c-fms, SIRP $\alpha$ overexpression partially reverses the $\mathrm{v}$-fms phenotype [42]. Two other family members have also been identified, SIRP $\beta$ (also known as CD172b) $[42,47]$ and SIRP $\gamma$ (also known as CD172g or SIRP $\beta 2$ ) [48], whose extracellular Ig-like domains are similar to that of SIRP $\alpha$. However, the cytoplasmatic regions of SIRP $\beta$ and SIRP $\gamma$ are different from that of $\operatorname{SIRP} \alpha$. SIRP $\beta$ has a very short cytoplasmatic tail with no signaling motifs. Instead, the transmembrane region contains a positively charged lysine residue, which can bind the immunoreceptor-tyrosine-based-activating-motif(ITAM-) carrying adaptor protein DNAX activation protein 12 (DAP12/KARAP) [49, 50]. SIRP $\gamma$ has no recognizable signaling motif or capability to interact with cytoplasmic signaling molecules and is therefore unlikely to generate intracellular signals [51]. CD47 has been shown to be a ligand for SIRP $\alpha[52,53]$ and SIRP $\gamma[54,55]$, but does not bind $\operatorname{SIRP} \beta$ [47]. The $\operatorname{CD} 47 / \operatorname{SIRP} \alpha$ interaction regulates not only a multitude of intercellular interactions in many body systems, such as the immune system where it regulates lymphocyte homeostasis [56, 57], dendritic cell (DC) maturation and activation [58], proper localization of certain DC subsets in secondary lymphoid organs [59-61], and cellular transmigration $[62,63]$, but also regulates cells of the nervous system (reviewed in $[64,65]$ ). An interaction between these two proteins also plays an important role in bone remodeling $[66,67]$. Cellular responses regulated by the CD47/SIRP $\alpha$ interaction are many times dependent on a bidirectional signaling through both receptors $[51,64,65]$ (Figure 1). The finding that CD47 on host cells can function as a "marker of self" and regulate phagocytosis by binding to $\operatorname{SIRP} \alpha[68]$ will be further described in a subsequent section. The interaction between CD47 and SIRP $\alpha$ has proven to be very specific species, as shown by the relatively weak binding of CD47 from mouse, rat, or cow to human SIRP $\alpha[69,70]$. In addition, the glycosylation of CD47 or SIRP $\alpha$ does not seem to be necessary for their interaction [70], but the level of N-glycosylation of SIRP $\alpha$ has, however, an impact on the interaction such that over glycosylation reduces the binding 


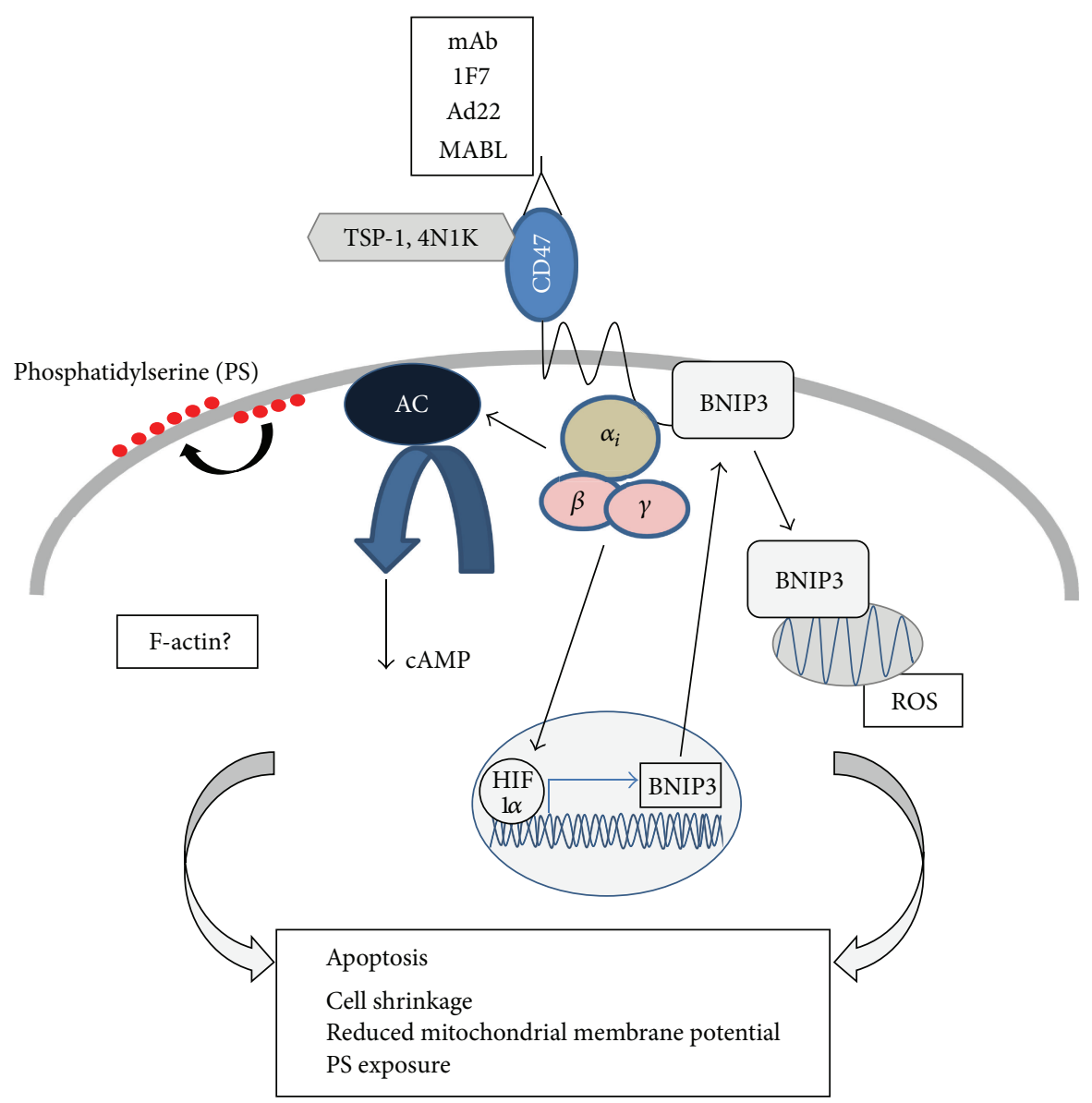

FIGURE 2: Mechanisms involved in mediating CD47-induced cell death. Ligation of CD47 by mAbs or TSP 1 induces apoptosis, which involves the activation of heterotrimeric Gi proteins, reduction in cAMP, and exposure of phosphatidylserine in the outer leaflet of the plasma membrane. It also induces the expression of the proapoptotic Bcl-2 family member BNIP3, its association with CD47, and subsequent translocation of BNIP3 to mitochondria. CD47-induced apoptosis may also involve ROS and F-actin.

of CD47 [71]. The long range disulfide bond between $\mathrm{Cys}^{33}$ in the $\mathrm{CD} 47 \mathrm{IgV}$ domain and $\mathrm{Cys}^{263}$ in the transmembrane domain is also important to establish an orientation of the $\mathrm{CD} 47 \mathrm{IgV}$ domain that enhances its binding to $\operatorname{SIRP} \alpha[29]$.

\section{CD47-Induced Apoptosis}

Ligation of CD47 by anti-CD47 mAbs was found to induce apoptosis in a number of different cell types. This phenomenon was first described in Jurkat $\mathrm{T}$ cells, in anti-CD3 activated but not in resting primary $\mathrm{T}$ cells, and in $\mathrm{B}$-cell chronic lymphocytic leukemia (B-CLL) cells $[72,73]$. CD47induced apoptosis can be induced by several different $\mathrm{mAbs}$; however, while some of these (e.g., Ad22, 1F7, or MABL) show potent apoptosis induction in suspension [73-76], others (e.g., B6H12 and 2D3) need to be immobilized to a surface to promote cell death $[72,77]$. Of the two SIRPfamily members known to bind the $\mathrm{CD} 47 \mathrm{IgV}$ domain (SIRP $\alpha$ and SIRP $\gamma$ ), SIRP $\alpha$ as a soluble Fc-fusion protein does not induce CD47-dependent apoptosis [78], while SIRP $\alpha$ or SIRP $\gamma$ bound onto the surface of beads induces apoptosis through CD47 in Jurkat T cells and the myelomonocytic cell line U937 [54]. In addition, TSP-1 or the CD47-binding TSP-1 CBD-peptide $4 \mathrm{~N} 1 \mathrm{~K}$ also induces CD47-dependent apoptosis $[74,75,78,79]$. Indeed, mice deficient in CD47 or TSP-1 sustain oxazolone-induced inflammation significantly longer than wild-type mice due to a deficiency in $\mathrm{T}$ cell apoptosis [79]. This form of cell death was initially described to be characterized by cell shrinkage, reduction in mitochondrial transmembrane potential, and exposure of phosphatidylserine (PS) on the cell surface, but to be independent of Fas (CD95) or TNF receptor signaling. Neither does CD47induced cell death include DNA fragmentation nor other nuclear features associated with "classical" apoptosis, and it is independent of cysteinyl aspartate protease (caspase) activation [72,73] (Figure 2). Furthermore, inhibitors of actin polymerization or mitochondrial electron transfer prevent CD47-induced PS exposure [77]. In support of a role for the actin cytoskeleton, peripheral blood mononuclear cells (PBMCs) from Wiskott-Aldrich syndrome (WAS) patients, where mutations in the WAS protein (WASP) results in defective Cdc42-induced regulation of the actin cytoskeleton [80], are resistant to CD47-induced apoptosis [77]. Although the mitochondrial transmembrane potential is affected in CD47induced apoptosis, it does not involve the mitochondrial 
release of cytochrome $\mathrm{c}$ or apoptosis-inducing factor (AIF), but does involve the production of reactive oxygen species (ROS) [81]. In Jurkat T cells, it was shown that the inhibition of Gi $\alpha$ signaling with pertussis toxin can counteract CD47induced apoptosis, that ligation of CD47 reduces intracellular cAMP levels, and that cAMP elevating agents prevents apoptosis by CD47 ligands [74]. This signaling pathway, which likely also involves reduced signaling through protein kinase A (PKA), is not only described in T cells, but also in several breast cancer cell lines [75]. In the latter cell type, it was shown that epidermal growth factor can inhibit the CD47 death pathway via protein kinase $\mathrm{C}$ (PKC) [75]. A yeast two-hybrid screen, where CD47 was used as bait, identified the proapoptotic Bcl-2 family member Bcl-2-homology-3- (BH3-) only protein $19 \mathrm{kDa}$ interacting protein-3 (BNIP3) [78]. In T cells, BNIP3 was found to physically associate with CD47, which prevents its degradation in proteasomes and sensitizes $\mathrm{T}$ cells to CD47-induced apoptosis [78, 79]. Ligation of CD47 induces the translocation of BNIP3 to mitochondria, and attenuation of BNIP3 activity inhibits CD47-induced apoptosis [78], which together suggests that BNIP3 is crucial as a mediator of this cell death pathway. Moreover, BNIP3 gene expression was found to be increased and regulated by hypoxia-inducible factor- $1 \alpha$ (HIF-1 $\alpha$ ) following the ligation of CD47 by single-chain fragments of an anti-CD47 mAb which kills B-CLL cell lines both in vitro and in vivo, where the knockdown of HIF-1 $\alpha$ represses CD47-induced cell death [82] (Figure 2). The finding that a Jurkat $\mathrm{T}$ cell clone lacking CD47 is resistant to Fas- (CD95-) induced apoptosis, but that expression of CD47 restores the sensitivity to Fas-ligation, suggested that CD47 can augment Fas-induced apoptosis via a mechanism that requires neither CD47 signaling nor its association with lipid rafts [83]. In fact, the lack of CD47 impairs important proapoptotic events downstream of Fas, such as loss of mitochondrial membrane potential, cytochrome c release, caspase activation, poly(ADP-ribose) polymerase (PARP) cleavage, and DNA fragmentation [83]. This function of CD47 is likely also important in primary cells, since $\mathrm{T}$ cells from CD47-deficient mice are protected from Fas-induced apoptosis [83].

In hematopoietic cells, CD47-induced apoptosis has been described in hematopoietic tumor cells $[54,72-74,76-78,81$, $82,84,85]$ and in activated primary $\mathrm{T}$ or $\mathrm{B}$ cells $[73,74,77,79]$. However, whether apoptosis can be induced through CD47 in nonactivated leukocytes is still somewhat unclear. The only situation where nonactivated $\mathrm{T}$ or B cells have been found to undergo CD47-induced apoptosis is when immobilized anti-CD47 $\mathrm{mAb}$ has been used [77], but not when using soluble CD47 ligands or mAbs known to induce apoptosis in activated cells or tumor cells $[73,74,79]$. Surprisingly, although $\mathrm{CD} 34^{+}$hematopoietic progenitors express CD 47 , they are resistant to $\mathrm{CD} 47$-induced apoptosis by either immobilized or soluble $\mathrm{mAb}[76,77]$. In addition, immature human monocyte-derived dendritic cells (iDCs) were described as resistant to CD47-induced apoptosis, following incubation with an immobilized CD47 mAb for 18 hours [77]. However, another study showed that freshly isolated human monocytes or human monocyte-derived iDC undergoes a rapid (within $60 \mathrm{~min}$ ) cell death in response to the CD47-ligand $4 \mathrm{~N} 1 \mathrm{~K}$
[86]. This cell death, which was described to occur in a subset of cells and where monocytes or iDC not affected by $4 \mathrm{~N} 1 \mathrm{~K}$ remain viable in culture, is associated with cellular features previously described for CD47-induced apoptosis, such as not only PS exposure, increased plasma membrane permeability, reduced mitochondrial membrane potential, caspase independence, but also included DNA fragmentation [86]. Thus, these findings suggest that although a subset of iDC may undergo CD47-induced cell death at an early time point, this may not be detectable at later time points. However, it raises the question if specific subsets of monocytes or iDCs are sensitive to this form of rapid cell death whereas others are resistant and maintain their viability in culture. In addition to hematopoietic cells, overexpression of CD47 can induces cell death of cultured cerebral cortical neurons, which is enhanced by the coexpression of SIRP $\alpha$ and prevented by brain-derived neurotrophic factor (BDNF) when CD47 and SIRP $\alpha$ are coexpressed [87]. Apoptosis in neurons overexpressing CD47, however, is dependent on caspases and apoptotic cells have condensed apoptotic nuclei with fragmented DNA [87]. It has also been shown that endothelial cells incubated under static conditions in the absence of flow increase their expression of TSP-1, which uses the $\mathrm{CD} 47 / \alpha_{\mathrm{v}} \beta_{3}$ integrin as a receptor to trigger endothelial cell apoptosis [88]. This mechanism also appears to be involved in endothelial cell apoptosis during proatherogenic turbulent flow conditions [89] and in mechanosensitive induction of apoptosis in fibroblasts [90]. TSP-1-mediated apoptosis, mapped to the type- 3 repeat/c-terminal domain of TSP-1, in promyelocytic leukemia cells (NB4-LR1) has also been suggested to depend on the engagement of both CD47 and the $\alpha_{\mathrm{v}} \beta_{3}$ integrin [91]. In contrast to the proapoptotic effects of CD47 described above, it was reported that the TSP1-derived peptide $4 \mathrm{~N} 1$ could abolish $\mathrm{C}_{2}$-ceramide-induced apoptosis in primary porcine thyroid cells by preventing reduction in intracellular cAMP levels, an effect blocked by the functional blocking antihuman $\mathrm{CD} 47 \mathrm{mAb}$ B6H12 [92]. A similar effect of $4 \mathrm{~N} 1$ peptide was also found to inhibit the cytotoxic effects of the anticancer drugs camptothecin and doxorubicin in thyroid carcinoma cells [93]. Although it is unclear how these effects of CD47-ligation can be explained in relation to the proapoptotic effects of this molecule, it is interesting to note that tumor cell TSP-1 overexpression has been linked to disease recurrence and decreased survival [9496], and it was suggested that this pathway could be one explanation behind drug resistance in thyroid cancers [93].

\section{Expression of CD47 in Erythrocytes}

4.1. Interaction of CD47 with Erythrocyte Membrane Protein Complexes. Mature erythrocytes express high levels of CD47, but do not express integrins, which early indicated that other important functions of CD47 could be expected in these cells. The fact that individuals with the $\mathrm{Rh}_{\text {null }}$ phenotype, which do not express any of the proteins of the Rh protein complex, only express about $25 \%$ of normal levels of CD47 suggested a close relation between CD47 and erythrocyte $\mathrm{Rh}$ proteins $[5,97]$. In the erythrocyte cell membrane, $\mathrm{Rh}$ 


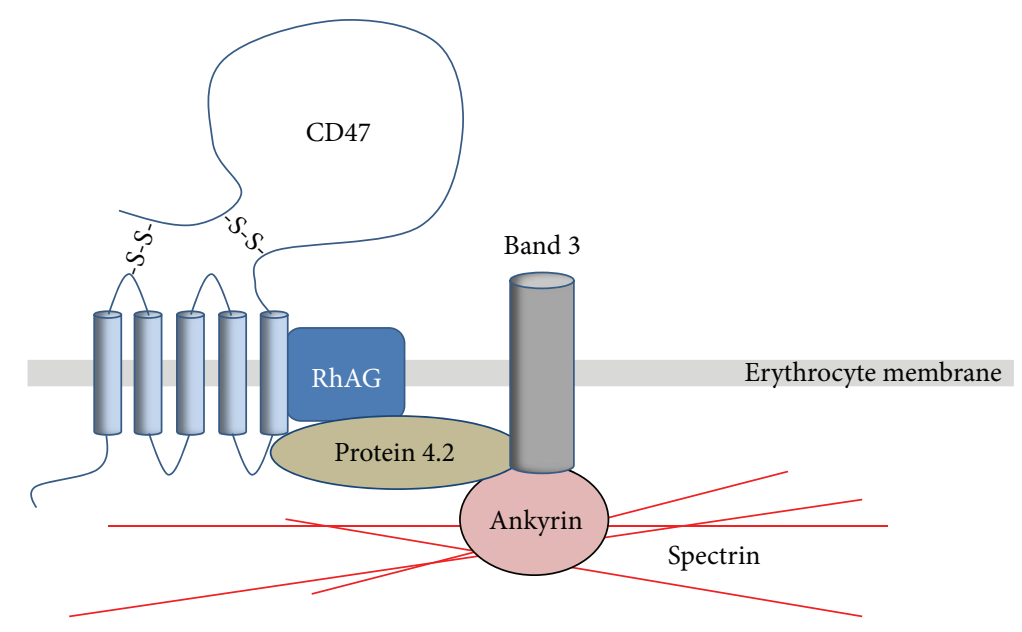

FIGURE 3: Association of CD47 with the Rh and band 3 complexes in the erythrocyte membrane. CD47 interacts with the Rh/RhAG complex and also associates with protein 4.2, which links CD47 to the band 3/ankyrin complex and the spectrin cytoskeleton. It is important to note that not all CD47 appears to be associated with this multiprotein complex in erythrocyte membranes.

polypeptides associate in a complex with many other proteins (e.g., Rh associated glycoprotein (RhAG), glycophorin B, LW, and CD47) [98]. Another erythrocyte membrane protein complex is formed by the band 3 anion exchanger and several other proteins (e.g., glycophorin A, protein 4.2, and ankyrin). The latter multiprotein complex mediates the anchorage of the erythrocyte membrane to the spectrin cytoskeleton [99, 100]. In addition, it has been suggested that the Rh complex and the band 3 complex may in fact be associated in the erythrocyte membrane [101]. Mutations in band 3, or complete band 3 deficiency, in human erythrocytes results in reduced expression of Rh polypeptides and RhAG [102] and results in a virtual lack of CD47 [101]. Moreover, human erythrocytes deficient in protein 4.2 also show a marked deficiency of CD47 as well as an altered glycosylation of RhAG [103]. When combining these finding, a hypothesis was put forward, which suggests that $\mathrm{CD} 47$ of the Rh complex may indeed form a link to the band 3 complex by binding to protein 4.2 [101] (Figure 3). Studies of protein mobility within the erythrocyte membrane have shown that CD47 is associated with the erythrocyte cytoskeleton as being a part of the Rh complex, but that CD47 is also present as a noncytoskeleton anchored pool which is more mobile in the erythrocyte membrane [104]. Thus, CD47 in erythrocytes may serve several different functions depending on its grade of mobility in the plasma membrane. It has been suggested that the freely mobile CD47 pool may be of importance to accumulate CD47 in specific membrane areas upon cell-cell contacts, for example, in order to efficiently interact with SIRP $\alpha$ on other cell types such as phagocytic cells [104]. Importantly, data from studies of murine erythrocytes have shown remarkable differences as compared with human erythrocytes, and the link between CD47, the Rh complex, and protein 4.2 in murine erythrocytes is not well understood. First, there are little or no Rh polypeptides in erythrocytes from band 3-deficient mice, while the expression of CD47 is only slightly reduced [101]. Second, erythrocytes from CD47deficient mice were found to contain normal amounts of murine Rh and RhAG polypeptides [105]. Third, erythrocytes from protein 4.2-deficient mice have normal amounts of CD47 [106]. Taken together, the total picture suggests that CD47 seems to interact with Rh polypeptides and protein 4.2 in human erythrocytes, whereas the interaction between $\mathrm{CD} 47, \mathrm{Rh}$ polypeptides, and proteins of the band 3 complex in murine erythrocytes is still unclear.

4.2. CD47 in Stored or Aged Erythrocytes. A progressive decrease in the CD47 expression level has been observed on human erythrocytes stored under blood bank conditions at $+4^{\circ} \mathrm{C}$ for more than 14 days [107-109] and in a mouse model of erythrocyte storage which tried to mimic human blood bank conditions [110]. However, the magnitude of reduction in CD47 expression was rather different, from a modest reduction of up to $6 \%$ at day 42 of storage [107], around 30\% reduction on day 28 of storage [108], to a more than $50 \%$ reduction on day 14 of storage [109]. Furthermore, a recent study indicated that the CD47 levels of erythrocytes stored for 35 days were not different from that of fresh cells [111]. The discrepancy between these findings may have several explanations, such as the exact storage conditions or methods for the quantification of erythrocyte CD47 expression levels. In addition, the loss of CD47 may also be sensitive to leukocytes remaining in the erythrocyte concentrates. Indeed, a gradual loss of CD47 from erythrocytes during storage was observed in stored erythrocytes irrespective of whether the buffy coat was removed or not before storage, although buffy coat removal resulted in an increased expression level of CD47 at all time points tested, showing a significant correlation between the number of remaining leukocytes and erythrocyte CD47 levels [108]. A study of cryopreserved leukoreduced erythrocytes was unable to detect any effects on erythrocyte CD47 expression levels [112]. Microparticles released in the blood from blood cells or endothelial cells have recently gained interest due to their possible role in regulating a variety of normal or pathological biological functions [113]. Such 
microparticles are also released from erythrocytes during cryopreservation or storage at $+4^{\circ} \mathrm{C}$, and these microparticles do among other erythrocyte membrane proteins also carry CD47 [112, 114]. Although the presence of CD47 on these microparticles suggests a mechanism for the observed loss of CD47 from stored erythrocytes, soluble CD47 has also been detected in the supernatants of erythrocytes stored at $+4^{\circ} \mathrm{C}$ [107]. In addition to a possible loss of CD47 on stored erythrocytes, a recent study also indicated that storage as well as experimental aging in vitro results in a conformational change of the CD47 protein [111]. This modification can be detected as a selectively increased binding of the anti$\mathrm{CD} 47 \mathrm{mAb} 2 \mathrm{D} 3$, which recognizes an epitope different from the epitope involved in the binding of TSP-1 or SIRP $\alpha$ and recognized by $\mathrm{mAb}$ B6H12 [111]. Normal erythrocyte aging in circulation is rather complicated to study in humans. However, the use of mouse models has been informative to further understand if the level of CD47 is changing during erythrocyte aging. In these models, biotin is injected intravenously to label all blood cells at one or two specific time points $[115,116]$. Analyses of circulating erythrocytes at later time points will then allow for discrimination between older biotin-positive and younger biotin-negative circulating erythrocytes $[115,116]$. Using this approach, it has been found that CD47 is gradually lost from the surface of circulating murine erythrocytes, where the oldest erythrocytes may have up to $30 \%$ lower CD47 expression levels as compared with younger erythrocytes $[115,117]$.

4.3. CD47 in Sickle Cell or Gaucher Disease. Sickle cell disease, caused by a mutation in the hemoglobin $\beta$ chain and a formation of insoluble intracellular aggregates of mutated hemoglobin, resulting in characteristic sickle shaped erythrocytes, is associated with severe vasoocclusive crisis [118, 119]. One important mechanism behind this pathology is the enhanced adhesion of sickle erythrocytes to vascular endothelium [118, 119]. CD47 was shown to play a role in the pathologic sequestration of sickle erythrocytes to vascular endothelium under shear stress by binding to TSP [120]. It has been found that the reticulocyte-enriched fractions of sickle erythrocytes are most efficiently binding to endothelial cells, that this function requires heterotrimeric $\mathrm{G}$ proteins and tyrosine kinase activity [121], and is mediated by $\alpha_{4} \beta_{1}$ integrins on the reticulocytes [19]. Interestingly, sickle erythrocytes also show an increased expression of the CD47 epitope recognized by mAb 2D3 [120]. In Gaucher's disease, a sphingolipidosis caused by glucocerebrosidase deficiency, macrophages accumulate glucosylceramide following the excess phagocytosis of erythrocytes, which converts splenic macrophages to pathogenic Gaucher cells [122]. Erythrocytes from patients with untreated Gaucher's disease have been found to have reduced levels of CD47, which can be reversed upon enzyme-replacement therapy [123]. It has been suggested that the anemia associated with the untreated disease can in part be explained by a combination of reduced CD47 levels together with other morphological erythrocyte abnormalities observed in this disease [123].

\section{Self versus Non-Self Discrimination in the Innate Immune System and Regulation of Phagocytosis by the CD47/SIRP $\alpha$ Interaction}

5.1. Self versus Non-Self Discrimination. The distinction between self and non-self is central to the maintenance of integrity in a multicellular organism and allows for a powerful and successful elimination of potentially dangerous pathogens, while carefully preserving healthy host cells and tissues. This distinction has been well studied in the adaptive immune response, which is specialized in the recognition of foreign peptides by virtue of small modifications to major histocompatibility complex (MHC) molecules made by these peptides [124]. For the innate immune system, recognition is thought to be based on a large extent on the recognition of specific microbial structures, pathogen-associated molecular patterns (PAMPs) [125]. The innate immune system of the host organism has through the evolution developed a group of receptors, pattern recognition receptors (PRRs), which serves to specifically recognize PAMPs [125]. In this way, the host may utilize a certain number of receptors, encoded in the genome, for the recognition of various evolutionary stable molecular pathogen-associated structures. While some of the PRRs (like the mannose receptor (MR)) recognize PAMPs directly [125], others (like complement receptors (CRs)) are specialized to detect products generated secondary to PAMP recognition [126]. However, a system based on specific recognition of "foreign" is clearly flawed as it prevents the recognition of anything that is also present on the organism's own cells. This can be very elegantly circumvented by a defense system that has very broad recognition, when it is combined with specific molecules that mark host cells and tissues as "self." Thus, recognition of "self" will inhibit the activation of innate immune cells, whereas the recognition of "missing self" allows for an immune response to proceed. In other words, a system where the own cells express a unique marker of self, not present on foreign cells, would make the distinction between self and foreign very simple. In that way, it would not matter if the organism's own cells express substances or ligands that are similar to those found on foreign cells/particles. Innate immune cells such as macrophages would only look for the presence of the "self marker" on the recognized particle, where the presence of self would release the recognized particle but the absence of self would allow for activation and destruction. This would significantly simplify the recognition process, as there would only be a need for a few broad specific recognition receptors instead of a countless number of foreign-specific receptors. It would also fulfill the criteria for a defense system that effectively recognize and destroy foreign objects but at the same time reduces the risk of damaging the organism's own structures. Such a system for macrophage activation would be analogous to the wellestablished "missing-self hypothesis" for natural killer (NK) cell activation [127]. NK cells recognize target cells by a range of activating receptors which also recognize ligands on many normal cells. However, in the NK cell system expression of self-MHC class I will protect the recognized cell via the ligation of NK cell inhibitory receptors specific for "self-" MHC class I [128]. It is, however, important to note, that NK 
cell inhibitory receptors are now described, which seem to have ligands other than MHC class I [129]. Upon the binding of self-MHC class I, ligated NK cell inhibitory receptors will recruit and activate the phosphatases SHP-1/SHP-2 that mediate the inhibition of NK cell activation [129]. NK cells thus spare cells whenever they express "markers of normal self," and eliminate them when these markers are absent or inadequately expressed. Other leukocytes also express molecules related to NK cell inhibitory receptors, further suggesting that similar mechanisms are operative also, for example, in macrophage activation [130]. Many of these inhibitory receptors recognize MHC class I [130], but the "marker of self" could in principle be any ubiquitously expressed surface molecule.

5.2. CD47 as a Marker of "Self". A new chapter in the understanding of CD47 and its functions started when CD47 was found to bind SIRP $\alpha[52,53]$. At the time, SIRP $\alpha$ was regarded as one of several immunoreceptors with cytoplasmic ITIM motifs, generally suggested to be involved in negative regulation of cellular functions, mediated by the recruitment of the tyrosine phosphatases SHP-1 and/or SHP-2 or the inositol phosphatase SHIP to the tyrosine phosphorylated ITIMs [131]. In addition, $\operatorname{SIRP} \alpha$ was found to be highly expressed in primary macrophages and macrophage cell lines [45], as well as in other myeloid cells such as monocytes, granulocytes, and dendritic cells [53]. In macrophages, SIRP $\alpha$ was found to negatively regulate signaling through tyrosine kinasedependent signaling pathways (e.g., FcERI) [132]. Although both SHP- 1 and SHP- 2 can bind to the phosphorylated SIRP $\alpha$ ITIMs, only SHP-1 has been associated with the inhibitory function of SIRP $\alpha$ in macrophages, similar to that of the NK cell inhibitory receptors [128], whereas SHP-2 associated with SIRP $\alpha$ leads to a phosphatase-dependent enhancement of the signal in many situations [133]. When studying CD47deficient mice, we were struck by the fact that CD47deficient bone marrow cannot reconstitute and engraft in lethally irradiated syngeneic wild-type recipient mice, while it engrafts normally in CD47-deficient recipient mice [134]. Our work on trying to understand this controversy first involved experiments where different leukocyte populations were transferred from CD47-deficient mice into wild-type recipient mice. However, we later simplified the system by studying transfusion of erythrocytes instead of leukocytes. The reason for this is that erythrocytes in contrast to many leukocyte populations have a long half-life in circulation, they do not divide, do not express MHC class I, and they do not home to extravascular tissues or organs. These studies showed that fresh erythrocytes isolated from the blood of CD47-deficient mice, labeled with a fluorescent cell tracker dye and transfused into wild-type recipient mice, have markedly reduced survival, whereas their half-life is normal in CD47-deficient recipients [68]. The clearance rate of such freshly isolated CD47-deficient erythrocytes is remarkably fast with complete clearance within 24 hours [68]. To put this in perspective, the average lifespan of murine erythrocytes in circulation is somewhere between 45 and 60 days, depending on the mouse strain investigated $[135,136]$. The rapid clearance of CD47-deficient erythrocytes from the circulation of wild-type recipient mice does not require complement, since CD47-deficient erythrocytes are also cleared from the circulation of complement factor 3(C3-) deficient mice. Neither is there a requirement for lymphocytes or antibodies to enable the clearance of CD47deficient erythrocytes from the circulation, since clearance is normal in Ragl-deficient mice, which lack mature $\mathrm{T}$ and B lymphocytes [68]. Rather, the transfused CD47-deficient erythrocytes that are eliminated from the circulation of wildtype mice are recognized and cleared by splenic red pulp macrophages, and the removal of these macrophages by splenectomy or by treatment with macrophage-toxic clodronate liposomes [137] abrogates the elimination of CD47deficient erythrocytes [68]. Furthermore, macrophage SIRP $\alpha$ is tyrosine phosphorylated upon contact with CD47 on erythrocytes, and when SIRP $\alpha$ on isolated splenic macrophages is blocked, it increases the level of phagocytosis of wild-type erythrocytes to that seen with CD47-deficient erythrocytes, whereas phagocytosis of the CD47-deficient erythrocytes is unaffected by the antibody treatment [68]. In addition, studies in $\operatorname{SIRP} \alpha$-mutant mice, where the cytoplasmic signaling domain of the receptor is deleted, have shown a shorter half-life of normal CD47-expressing erythrocytes in these mice, which also present with mild anemia [138]. Such spontaneous anemia is, however, not seen in CD47deficient mice, suggesting that CD47 could also be needed on the macrophages to facilitate the clearance of erythrocytes in the spleen. However, lack of CD47 on platelets also results in very rapid clearance when transfused into wildtype recipients, and both CD47-deficient mice and SIRP $\alpha$ mutant mice have a mild spontaneous antibody-independent thrombocytopenia $[139,140]$. Altogether, these findings indicated that all erythrocytes can be phagocytosed by splenic red pulp macrophages when SIRP $\alpha$ is blocked or CD47 is missing, and that these macrophages must have a receptor for erythrocytes. Indeed, we have identified LDL receptor-related protein (LRP-1), which by recognizing calreticulin on the surface of normal erythrocytes can mediate phagocytosis of untreated CD47-deficient erythrocytes [141, 142]. By showing that macrophages in the splenic red pulp can recognize normal circulating erythrocytes, but that these macrophages do not phagocytose erythrocytes as long as they display CD47 on their surface, these findings were the first to prove that macrophages are perfectly capable of recognizing "normal" host cells and rely on "self" recognition for proper function. In addition, it also demonstrated major similarities between mechanisms for "self" recognition in NK cells and macrophages [128]. Based on the findings that unopsonized erythrocytes lacking CD47 can be phagocytosed by splenic macrophages, and that the CD47/SIRP $\alpha$ interaction can potently inhibit the prophagocytic mechanism operating in that situation, we next hypothesized that the CD47/SIRP $\alpha$ interaction might as well be able to negatively regulate phagocytosis of opsonized erythrocytes, and that for the cells of the innate immune systems front line defense (i.e., macrophages and DC) there would be a balance between signals from activating receptors (e.g., $\mathrm{Fc} \gamma \mathrm{R}$ or $\mathrm{CR}$ ) and the inhibitory signal from SIRP $\alpha$ ligated by target cell $\mathrm{CD} 47$. Indeed, the CD47/SIRP $\alpha$ interaction can also regulate 
phagocytosis of IgG-opsonized or complement opsonized erythrocytes as well as other opsonized host cells, making CD47-deficient cells severely sensitive to being phagocytosed [139, 143-145]. In addition, CD47-deficient mice are severely sensitive to experimental autoimmune hemolytic anemia (AIHA) and experimental thrombocytopenia $[139,146]$. On an autoimmune background prone to develop spontaneous AIHA, lack of CD47 results in a more rapid and lethal AIHA [146]. Using motheathen viable $\left(\mathrm{me}^{\mathrm{v}} / \mathrm{me}^{\mathrm{v}}\right)$ mice, which only have about $20 \%$ of normal levels of SHP-1, but normal levels of SHP-2 [147-149], we could pinpoint the role of these phosphatases in mediating the phagocytosis inhibitory effect of the CD47/SIRP $\alpha$ interaction in vivo. When transfused into $\mathrm{me}^{\mathrm{v}} / \mathrm{me}^{\mathrm{v}}$ mice, IgG-opsonized wild-type erythrocytes are cleared with the same rapid kinetics as seen with equally opsonized CD47-deficient erythrocytes [145], showing that at that particular signaling strength through prophagocytic $\mathrm{Fc} \gamma$ receptors, the level of CD47 on normal erythrocytes was not enough to prevent phagocytosis if the SHP-1 level was reduced by about $80 \%$. In contrast, the prophagocytic signaling mediating phagocytosis of unopsonized CD47-deficient erythrocytes (presumably mediated by LRP-1) is likely much weaker, since unopsonized wild-type erythrocytes are not cleared with the same rapid kinetics as CD47-deficient cells in $\mathrm{me}^{\mathrm{v}} / \mathrm{me}^{\mathrm{v}}$ mice [145]. However, while unopsonized CD47 heterozygous erythrocytes (expressing about $50 \%$ of the CD47 found on wild-type erythrocytes) show normal halflife when transfused into wild-type recipients, they were found to be cleared more rapidly when transfused into $\mathrm{me}^{\mathrm{v}} / \mathrm{me}^{\mathrm{v}}$ mice [145]. These findings thus proposed that a reduction of the CD47 level to $50 \%$ of normal, in combination with a strongly reduced level of SHP-1 in the macrophages, together weakened the inhibitory signaling through SIRP $\alpha$ such that clearance of unopsonized erythrocytes was allowed. Furthermore, the rate of phagocytosis of IgG-opsonized erythrocytes is distinctly regulated by the amount of CD47 present on the surface of the erythrocytes both in vivo and in vitro [150]. Thus, activation of phagocytosis in a macrophage in contact with a target erythrocyte (or any other host cell) can be viewed as a balance between signals from activating receptors (i.e., Fc $\gamma$ R, CR, or LRP-1) and the inhibitory signal from SIRP $\alpha$ ligated by target cell CD47. In the macrophage, neither signal appears to be dominant, but rather the decision to phagocytose a target host cell is based on an integration of positive prophagocytic signals and inhibitory CD $47 / \operatorname{SIRP} \alpha$ signaling (Figure 4(a)). The same functional regulation also seems to be operating in DCs [134] and in microglia [151]. In hemophagocytic lymphohistiocytosis, hematopoietic stem cells are phagocytosed by bone marrow macrophages as a result of systemic inflammation [152]. In this disease, hematopoietic stem cells were found to express reduced levels of CD47 [153], which shows that pathological conditions may occur where a combination of inflammatory macrophage activation and reduced expression of CD47 results in a severe loss of critical cell types [153]. However, not all prophagocytic receptors seem to be regulated by the CD47/SIRP $\alpha$ interaction. Although F $\gamma \gamma$ receptor-mediated phagocytosis of IgG-opsonized oxidatively damaged erythrocytes is strongly inhibited by the CD47/SIRP $\alpha$ interaction, scavenger receptor-mediated uptake of unopsonized oxidized erythrocytes turned out to be insensitive to this inhibitory mechanism [154]. The mechanism whereby recruitment of SHP-1 to SIRP $\alpha$ can inhibit phagocytosis has been suggested to involve the tyrosine kinase Syk and phosphoinositide 3 kinase (PI3 kinase) [144]. More recently, it was suggested that SHP-1 mediates dephosphorylation of nonmuscular myosin IIA at the phagocytic synapse between the phagocyte and a host cell, as a result of the interaction between macrophage SIRP $\alpha$ and CD47 on the host cell, which brings further insight into the mechanism behind phagocytosis inhibition by the $\mathrm{CD} 47 / \operatorname{SIRP} \alpha$ interaction [155].

Based on the seemingly important interaction between CD47 and SIRP $\alpha$ to prevent phagocytosis of host cells, and the fact that CD47-deficient cells are rapidly phagocytosed when transfused into wild-type mice, it is clearly a puzzle why CD47-deficient mice do not present with a more severe phenotype where the macrophages phagocytose a large fraction of the CD47-deficient cells in those mice [68]. However, this phenomenon is rather similar to what is described in $\beta 2$ microglobulin deficient mice, which lack expression of MHC class I but where the NK cells still do not attack and destroy host cells and also show hyporeactivity to cells carrying ligands for activating NK cell receptors, cells which are efficiently killed by wild-type NK cells [156]. One explanation proposed for this function in NK cells is that inhibitory NK cell receptors need to interact with "self-" MHC class I in order for the NK cell to become "licenced" and able to become activated and kill target cells lacking or expressing reduced levels of "self-" MHC class I [156]. By investigating the ability to phagocytose CD47-deficient cells in mice where CD47 was expressed by hematopoietic cells, nonhematopoietic cells, or both, the phagocytic "tolerance" to cells lacking CD47 in CD47-deficient mice was recently proposed to function in a similar way [157]. It was found that macrophages developing in an environment where nonhematopoietic cells lack CD47 become "tolerant" to cells lacking CD47, which allowed CD47-defcient leukocytes to avoid clearance. Curiously, this did not involve erythrocytes, which were cleared by splenic macrophages also in the bone marrow chimeras where nonhematopoietic cells lacked CD47 and macrophages had become "tolerant" [157]. The latter phenomenon has so far not been explained, but may suggest that phagocytosis of erythrocytes is regulated differently from that of leukocytes. Although CD47-deficient macrophages express normal amounts of SIRP $\alpha$, which can also become tyrosine phosphorylated upon contact with CD47 expressing cells (Oldenborg et al., unpublished observations and [158]), it is possible that the "tolerance" to CD47-deficient cells that develop in CD47-deficient mice has to do with tuning of intracellular signaling pathways. In favor of such a hypothesis is the observation that transfused IgG-opsonized wild-type erythrocytes are cleared from the circulation at a significantly slower rate in CD47-deficient mice, as compared with that seen in wild-type recipient mice (Oldenborg et al. unpublished observations). This is unlikely due to a different expression of $\mathrm{Fc} \gamma$ receptors in CD47-deficient mice, since CD47-deficient IgG-opsonized erythrocytes are cleared with 


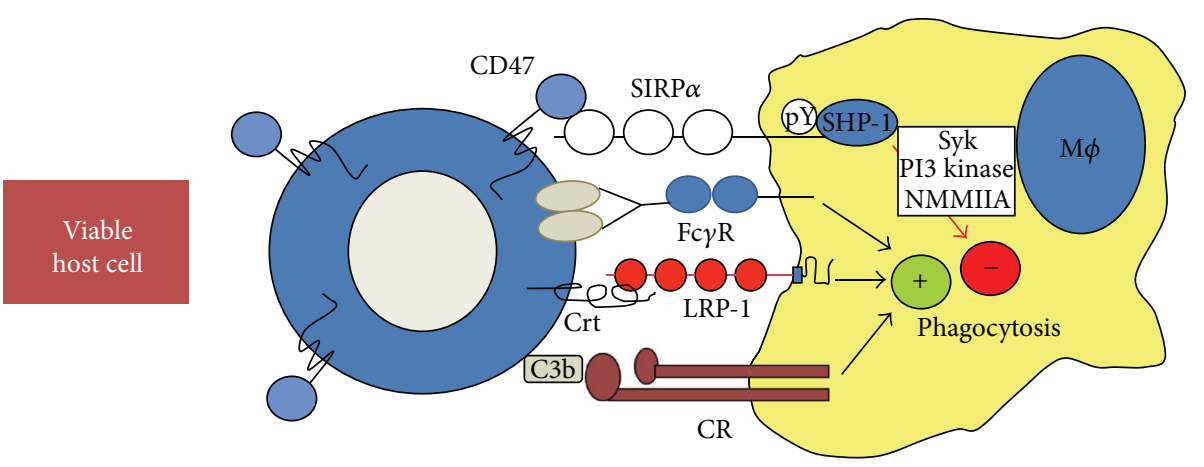

(a)

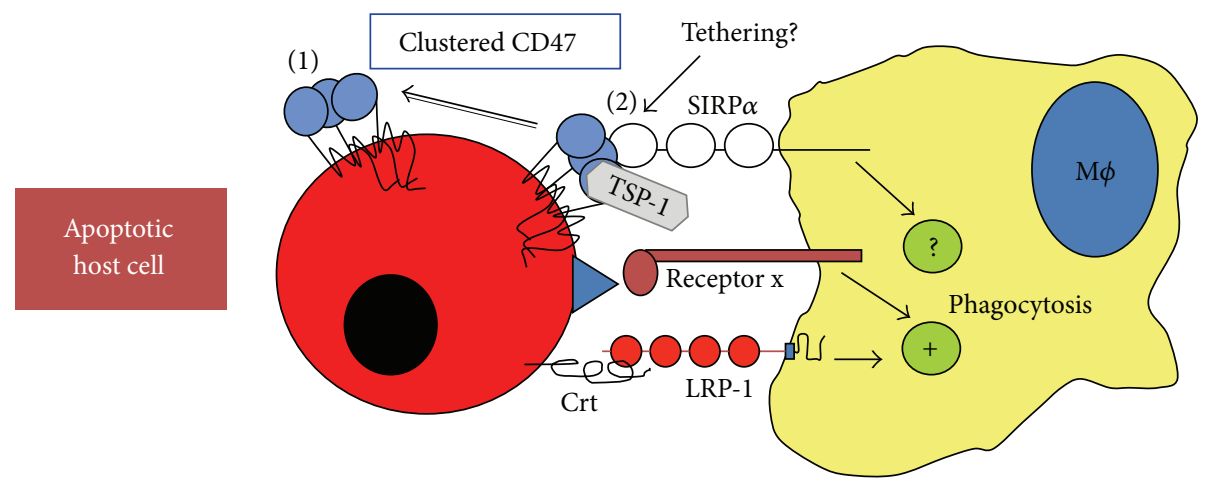

(b)

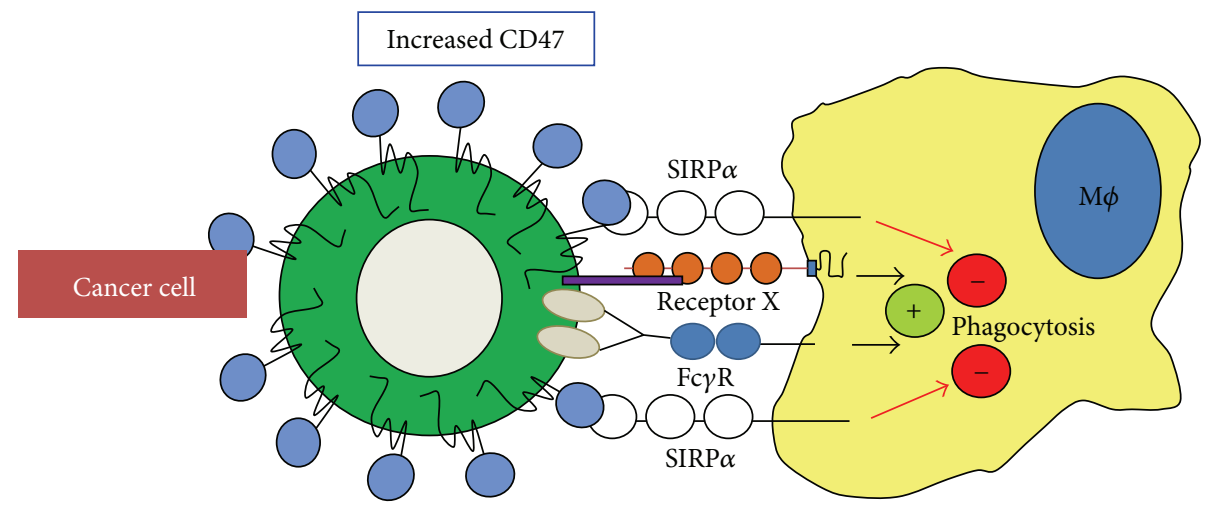

(c)

FIGURE 4: CD47 regulates phagocytosis of host cells by interacting with SIRP $\alpha$. (a) CD47 on viable normal host cells can bind to SIRP $\alpha$ on a phagocytic cell (e.g., a macrophage $(\mathrm{M} \phi)$ ), which induces tyrosine phosphorylation of SIRP $\alpha$ ITIMS and recruitment of SHP-1. This can inhibit prophagocytic signaling through $\mathrm{Fc} \gamma$ receptors, complement receptors (CR), or LRP-1. Phagocytosis inhibition may involve signaling through Syk and PI3 kinase and inhibition of nonmuscle myosin type IIA (NMMIIA). (b) On apoptotic cells, CD47 becomes clustered in the plasma membrane and may be segregated away from domains containing ligands for prophagocytic receptors, here exemplified by calreticulin (crt) binding to LRP-1. However, most likely this principle involves also other prophagocytic receptors (receptor x). Clustered CD47 may also bind to SIRP $\alpha$ without inducing inhibition of phagocytosis, but may rather promote tethering of the apoptotic cell to the phagocyte. This function may also involve TSP-1 and so far uncharacterized mechanisms that can also promote phagocytosis. (c) Cancer cells may increase their expression of CD47 to strengthen the inhibitory signals through SIRP $\alpha$ and to more potently inhibit phagocytosis mediated by Fc $\gamma$ receptors and other prophagocytic receptors (receptor $\mathrm{x}$ ).

the same kinetics in both wild-type and CD47-deficient recipient mice (Oldenborg et al. unpublished observations).

5.3. CD47 and Phagocytosis of Apoptotic Cells. Apoptosis is a physiological process of programmed cell death which is important for embryologic development, maintenance of homeostasis, and elimination of damaged cells. An important event related to this process is the rapid uptake of apoptotic cells or apoptotic bodies by phagocytic cells. The efficacy of this process in the body is shown by the fact that apoptotic cells are apparently removed with such extremely high 
efficiency that apoptotic cells are very hard to detect in tissues under normal physiological conditions. It has even been suggested that if apoptotic cells are in fact detected in vivo, this may indicate a possibility of defects in their clearance or the presence of a large overload of apoptotic cells [159-162]. The largest part of apoptotic cell phagocytosis is mediated not only by professional phagocytes like macrophages and DCs, but also to some extent by nonprofessional phagocytes such as fibroblasts; epithelial cells and stromal cells are equipped with this function [160]. One example of the latter phenomenon is the phagocytosis of apoptotic mammary epithelial cells by bystander epithelial cells during mammary gland involution $[163,164]$. When CD47 was identified as a cell surface protein on host cells that can negatively regulate their phagocytosis through $\operatorname{SIRP} \alpha$, one important question was to understand if this signaling pathway is altered during apoptosis to facilitate uptake of apoptotic cells. One hypothesis would be that apoptotic cells downregulate the amount of CD47 on their surface, which together with an increased amount of prophagocytic ligands exposed during apoptosis would result in phagocytosis of the dead cells. Indeed we found a reduced expression of CD47 on apoptotic fibroblasts and neutrophils [141], but curiously not on apoptotic Jurkat T cells [141] or apoptotic murine thymocytes [165]. This issue became even more confusing when apoptotic murine T cells lacking CD47, in contrast to the solid data showing that CD47 on host cells inhibits phagocytosis by macrophages, were found to be phagocytosed less efficiently by macrophages than equally apoptotic CD47 wild-type T cells $[143,165]$. In apoptotic murine T cells, CD47 was rather found to be important in mediating tethering of the apoptotic cells to the phagocyte $[143,165]$. In addition, CD47 is redistributed into patches on the apoptotic cell surface, areas of the plasma membrane which are different than those harbouring clusters of proteins that function as ligands for prophagocytic receptors $[141,143]$. Thus, one possibility would be that the segregation of CD47 away from these phagocytosis promoting ligands could allow for tethering mediated by the CD47/SIRP $\alpha$ interaction, but that $\operatorname{SIRP} \alpha$ would be too far away from the prophagocytic receptors to be involved in negative regulation (Figure 4(b)). Another very interesting hypothesis was recently suggested, which shed new light on this process. As described above in Section 4.2 experimentally oxidized erythrocytes, as well as erythrocytes stored in blood bank conditions, showed enhanced expression of the $\mathrm{CD} 47$ epitope recognized by $\mathrm{mAb}$ $2 \mathrm{D} 3$, suggesting a conformational change in the CD47 IgV domain [111]. Importantly, this is associated with an increased binding of TSP-1 to CD47, which together could generate a new binding site for $\operatorname{SIRP} \alpha$ that induces a prophagocytic signal instead of the "normal" inhibitory CD47/SIRP $\alpha$ signal [111]. However, this very interesting hypothesis still has to also be investigated in the context of macrophage phagocytosis of apoptotic nucleated cells such as neutrophils or $\mathrm{T}$ cells. Thus, CD47 may operate in several different ways during cellular senescence in order to switch its normal phagocytosis-preventing role to rather facilitate and promote the phagocytosis of senescent cells. LRP-1 is a multifunctional scavenger receptor, shown to be involved in mediating uptake of apoptotic cells [141, 166, 167], and as already mentioned it can also bind to calreticulin on viable erythrocytes to induce phagocytosis if the inhibitory CD47/SIRP $\alpha$ interaction is not strong enough [141, 142] (Figure 4(b)). Glucocorticoids are powerful in treatment of inflammatory conditions, which can be attributed to their ability to downregulate production of and cellular responses to proinflammatory cytokines and their ability to inhibit the recruitment of inflammatory cells $[168,169]$. However, another mechanism whereby glucocorticoids may also reduce inflammation is to stimulate phagocytosis of apoptotic cells [170, 171]. Interestingly, glucocorticoid treatment of macrophages results in increased macrophage expression of LRP-1 and increased phagocytosis of apoptotic cells or viable CD47-deficient erythrocytes [142].

5.4. CD47 and Regulation of Tumor Cell Phagocytosis. Since CD47 can inhibit phagocytosis of host cells, and the amount of CD47 on the cell surface is clearly important in determining the phagocytosis efficiency of macrophages, this also raised the question on whether cells such as tumor cells can also increase their CD47 expression levels in order to escape macrophage elimination. Indeed, early studies showed that ovarian carcinoma cell lines express increased levels of CD47 [6,7], the functional significance of which was unclear at that time. More recently, an enhanced expression of CD47 has been reported for murine myeloid leukemias, as well as human normal and leukemic hematopoietic stem cells and many human solid tumors [172-174], and that increased CD47 expression is associated with reduced patient survival in AML and solid tumors [173, 174]. To challenge the hypothesis that CD47 on the leukemic cells protects from phagocytosis by macrophages and supports tumor cell growth, a xenogenic mouse model was used to study a particular human AML clone (MOLM-13) with very low endogenous CD47 expression. Expression of murine CD47 in MOLM-13 cells and transplantation of MOLM-13 clones expressing low or high levels of CD47 showed an enrichment and spreading of the CD47-high expressing clones to many bones of recipient mice, while the CD47-low clones showed minimal engraftment [172]. Depletion of macrophages in recipient mice allows for engraftment of CD47-low clones, and macrophage phagocytosis of AML cells both in vitro and in vivo is selective for tumor cells expressing low amounts of CD47 [172]. Importantly, by blocking SIRP $\alpha$ on macrophages, phagocytosis of CD47-high AML cells is increased to that seen with CD47-low clones [172]. Thus, these findings strongly suggest that an increased CD47 expression level on tumor cells could serve to avoid macrophage clearance and promote dissemination of tumor cells (Figure 4(c)). It was also recently shown that treatment serving to block the CD47/SIRP $\alpha$ interaction can result in elimination of AML stem cells in a xenogenic model [175]. Furthermore, inline with our original finding that the CD47/SIRP $\alpha$ pathway also potently inhibits Fc $\gamma$ receptor-mediated phagocytosis of IgGopsonized host cells $[139,145,146,150]$, it has been shown that antibody-mediated blocking of CD47/SIRP $\alpha$ signaling promotes phagocytosis of non-Hodgkin lymphoma cells treated with rituximab [176] and antibody-dependent cellular cytotoxicity (ADCC) against Her2/Neu-positive breast cancer cells treated with traztusumab [177]. Thus, blocking 
the CD47/SIRP $\alpha$ interaction may prove to be a powerful tool in the treatment of various tumors.

5.5. CD47 and Regulation of Xenografts. While organ transplantation is an important procedure to treat end-stage organ failure, it is hampered by a shortage of organ donors. To solve this problem, it has been suggested that pigs could serve as donors of organs, tissues, or cells to be transplanted into humans (i.e., xenotransplantation) $[158,178]$. Both the innate and adaptive immune system participates in the rejection of xenogenic transplants [178], the exact details of which is outside the scope of the present paper. However, of particular interest here are the findings suggesting that even in the absence of a functional adaptive immune system and in the absence of NK cells (both of which react to cell surface determinants of xenogenic cells recognized as nonself), rejection of xenogenic cells and tissues is seen, which suggests that macrophages could play an important role in this process [158]. Indeed, in studies of transplantation of pancreatic islets $[179,180]$ or hematopoietic cells [181] from pigs to mice, macrophage depletion significantly enhances engraftment. The ability of macrophage $\operatorname{SIRP} \alpha$ to inhibit phagocytosis by binding to CD47 on a target cell, and the fact that this interaction is rather species specific suggested that this interaction could play a role in macrophage-mediated clearance of xenogenic cells. Indeed, it was found that porcine CD47 cannot bind to murine $\operatorname{SIRP} \alpha$ and induce tyrosine phosphorylation of the SIRP $\alpha$ ITIMs [182], which could explain the rapid clearance of porcine hematopoietic cells by macrophages both in vitro and in vivo $[181,182]$. However, expression of murine CD47 in porcine cells markedly inhibits macrophage-mediated phagocytosis of these cells in vitro and prolongs their survival in vivo [182]. Although a human $\operatorname{SIRP} \alpha$ fusion protein was found to bind to porcine CD47 [69], porcine CD47 does not activate human SIRP $\alpha$ [183]. As a result, porcine hematopoietic cells are rapidly phagocytosed by human macrophages, but expression of human CD47 in porcine cells results in attenuated phagocytosis by human macrophages [183]. These findings indicate that transgenic pigs expressing human CD47 could be an important possibility to further help reducing the rejection of porcine cells in xenotransplantation.

\section{CD47 in Bone Homeostasis}

The finding that CD47, by binding to $\operatorname{SIRP} \alpha$, could regulate rat alveolar macrophage fusion and formation of multinucleated giant cells in vitro [184] suggested a function also in regulating formation of bone-resorbing osteoclasts and regulation of bone homeostasis. Using functional blocking monoclonal antibodies against either $\operatorname{CD} 47$ or $\operatorname{SIRP} \alpha$, the formation of tartrate resistant acid phosphatase $(\mathrm{TRAP})^{+}$multinucleated osteoclasts is strongly inhibited in murine cell culture systems in vitro [66]. This finding can also be confirmed in vivo, since CD47-deficient mice have reduced numbers of osteoclasts in bone [66] and are protected from tumor metastasis and subsequent bone resorption [185]. There are a few hypotheses presented to explain the mechanism whereby the interaction between CD47 and $\operatorname{SIRP} \alpha$ promotes osteoclastogenesis. One suggests that binding of CD47 results in SIRP $\alpha$ tyrosine phosphorylation and subsequent recruitment of SHP1 to the phosphorylated ITIMs, which next would mediate dephosphorylation of nonmuscle cell myosin IIA to promote fusion and formation of osteoclasts [67]. This hypothesis is contrasted by a study of $\operatorname{SIRP} \alpha$ mutant mice, expressing a truncated nonsignaling SIRP $\alpha$ cytoplasmic domain, where cultures of bone marrow cells generated the same number of osteoclasts of the same size, as found in wild-type bone marrow cultures [186]. The important observation made in the latter study was that osteoclasts generated in $\operatorname{SIRP} \alpha$ mutant mice had an increased bone resorbing activity, suggesting that $\operatorname{SIRP} \alpha$ negatively regulates this function in osteoclasts [186]. The contradictory findings presented regarding a possible role of signaling through either $\mathrm{CD} 47$ or $\operatorname{SIRP} \alpha$ during fusion of preosteoclasts and formation of multinucleated osteoclasts must also be put in context of the originally presented hypothesis that the interaction between CD47 and $\operatorname{SIRP} \alpha$ may mainly facilitate cell fusion by promoting cell-cell adhesion and bringing the plasma membranes of two cells close enough to facilitate cell fusion [187]. Here it has also been highlighted that CD47 may interact with the shorter SIRP $\alpha$ isoform having only one extracellular IgV domain, which would further reduce the distance between two opposing cellular membranes where cell fusion could take place [187].

\section{Concluding Remarks and Future Perspectives}

CD47 can regulate many important physiological cellular mechanisms by interacting with integrins, TSP-1, or SIRP $\alpha$. As outlined above, much knowledge has been collected over the past two decades, but much is probably still to be discovered regarding the functions of this protein. There are several areas where one can assume that further progress may result in new novel ways to interfere with biological mechanisms in pathological conditions. One such example is the ability to induce apoptosis by ligating CD47. Although CD47 is expressed by virtually all cells in the body, in healthy as well as pathological cells, the data so far indicates that CD47-induced apoptosis may still be a way to kill, for example, tumor cells, since it appears that tumor cells and activated cells are much more sensitive to this cell death mechanism than nonactivated naïve cells or hematopoietic stem cells. The ability of CD47 to inhibit phagocytosis is clearly an important mechanism whereby innate cells as macrophages or dendritic cells can discriminate between self and non-self, and maintain tolerance to host cells. In the field of xenotransplantation, further development and research to create xenotransplants carrying human CD47 may prove important to obtain even better conditions where xenogenic cell, tissues, or organs can be tolerated when transplanted into humans. In the field of cancer research, where tumor cells may express higher levels of CD47 as a way of avoiding phagocytosis and clearance by phagocytic cells, and where CD47-blocking antibodies have been shown 
to promote clearance of and to reduce the dissemination of tumor cells, brings hope that careful development of reagents that can block the CD47/SIRP $\alpha$ interaction may indeed be useful to treat many forms of cancer without having too much of a negative side effect in terms of inducing clearance of host cells. Also in the field of bone research, one may suggest that manipulation of the interaction between CD47 and $\operatorname{SIRP} \alpha$ may be a way to modulate bone resorption and to prevent osteoporosis. However, data showing that these two proteins may also be involved in regulating bone formation [67] indicate that manipulation of this signaling system in bone tissue may be more complicated.

\section{Acknowledgments}

This paper is supported by Grants from the Swedish Research Council (2010-4286), the Faculty of Medicine, Umeå University, and a Young Researcher Award from Umeå University.

\section{References}

[1] F. P. Lindberg, H. D. Gresham, E. Schwarz, and E. J. Brown, "Molecular cloning of integrin-associated protein: an immunoglobulin family member with multiple membrane-spanning domains implicated in $\alpha_{\mathrm{V}} \beta_{3}$-dependent ligand binding," Journal of Cell Biology, vol. 123, no. 2, pp. 485-496, 1993.

[2] E. Brown, L. Hooper, T. Ho, and H. Gresham, "Integrinassociated protein: a $50-\mathrm{kD}$ plasma membrane antigen physically and functionally associated with integrins," Journal of Cell Biology, vol. 111, no. 6, pp. 2785-2794, 1990.

[3] F. P. Lindberg, H. D. Gresham, M. I. Reinhold, and E. J. Brown, "Integrin-associated protein immunoglobulin domain is necessary for efficient vitronectin bead binding," Journal of Cell Biology, vol. 134, no. 5, pp. 1313-1322, 1996.

[4] F. P. Lindberg, D. C. Bullard, T. E. Caver, H. D. Gresham, A. L. Beaudet, and E. J. Brown, "Decreased resistance to bacterial infection and granulocyte defects in IAP-deficient mice," Science, vol. 274, no. 5288, pp. 795-798, 1996.

[5] F. P. Lindberg, D. M. Lublin, M. J. Telen et al., "Rh-related antigen CD47 is the signal-transducer integrin-associated protein," Journal of Biological Chemistry, vol. 269, no. 3, pp. 1567-1570, 1994.

[6] I. G. Campbell, P. S. Freemont, W. Foulkes, and J. Trowsdale, "An ovarian tumor marker with homology to vaccinia virus contains an IgV- like region and multiple transmembrane domains," Cancer Research, vol. 52, no. 19, pp. 5416-5420, 1992.

[7] L. G. Poels, D. Peters, Y. van Megen et al., "Monoclonal antibody against human ovarian tumor-associated antigens," Journal of the National Cancer Institute, vol. 76, no. 5, pp. 781-791, 1986.

[8] M. I. Reinhold, F. P. Lindberg, D. Plas, S. Reynolds, M. G. Peters, and E. J. Brown, "In vivo expression of alternatively spliced forms of integrin-associated protein (CD47)," Journal of Cell Science, vol. 108, no. 11, pp. 3419-3425, 1995.

[9] E. H. Y. Lee, Y. P. Hsieh, C. L. Yang, K. J. Tsai, and C. H. Liu, "Induction of integrin-associated protein (IAP) mRNA expression during memory consolidation in rat hippocampus," European Journal of Neuroscience, vol. 12, no. 3, pp. 1105-1112, 2000.

[10] S. Kaur, S. A. Kuznetsova, M. L. Pendrak et al., "Heparan sulfate modification of the transmembrane receptor CD47 is necessary for inhibition of T Cell receptor signaling by thrombospondin1," Journal of Biological Chemistry, vol. 286, no. 17, pp. 1499115002, 2011.

[11] H. D. Gresham, J. L. Goodwin, P. M. Allen, D. C. Anderson, and E. J. Brown, "A novel member of the integrin receptor family mediates Arg-Gly-Asp-stimulated neutrophil phagocytosis," Journal of Cell Biology, vol. 108, no. 5, pp. 1935-1943, 1989.

[12] D. Cooper, F. P. Lindberg, J. R. Gamble, E. J. Brown, and M. A. Vadas, "The transendothelial migration of neutrophils involves integrin-associated protein (CD47)," Proceedings of the National Academy of Sciences of the United States of America, vol. 92, no. 9, pp. 3978-3982, 1995.

[13] C. A. Parkos, S. P. Colgan, T. W. Liang et al., "CD47 mediates post-adhesive events required for neutrophil migration across polarized intestinal epithelia," Journal of Cell Biology, vol. 132, no. 3, pp. 437-450, 1996.

[14] Y. Liu, D. Merlin, S. L. Burst, M. Pochet, J. L. Madara, and C. A. Parkos, "The role of CD47 in neutrophil transmigration: increased rate of migration correlates with increased cell surface expression of CD47," Journal of Biological Chemistry, vol. 276, no. 43, pp. 40156-40166, 2001.

[15] R. M. Senior, H. D. Gresham, G. L. Griffin, E. J. Brown, and A. E. Chung, "Entactin stimulates neutrophil adhesion and chemotaxis through interactions between its Arg-Gly-Asp (RGD) domain and the leukocyte response integrin," Journal of Clinical Investigation, vol. 90, no. 6, pp. 2251-2257, 1992.

[16] J. Chung, A. G. Gao, and W. A. Frazier, "Thrombspondin acts via integrin-associated protein to activate the platelet integrin $\beta_{\mathrm{llb}} \beta_{3}$," Journal of Biological Chemistry, vol. 272, no. 23, pp. 14740-14746, 1997.

[17] J. Chung, X. Q. Wang, F. P. Lindberg, and W. A. Frazier, "Thrombospondin-1 acts via IAP/CD47 to synergize with collagen in $\alpha 2 \beta 1$ - mediated platelet activation," Blood, vol. 94, no. 2, pp. 642-648, 1999.

[18] X. Q. Wang and W. A. Frazier, "The thrombospondin receptor CD47 modulates and associates with $\alpha 2 \beta 1$ integrin in vascular smooth muscle cells," Molecular Biology of the Cell, vol. 9, no. 4, pp. 865-874, 1998.

[19] J. E. Brittain, J. Han, K. I. Ataga, E. P. Orringer, and L. V. Parise, "Mechanism of CD47-induced $\alpha 4 \beta 1$ integrin activation and adhesion in sickle reticulocytes," Journal of Biological Chemistry, vol. 279, no. 41, pp. 42393-42402, 2004.

[20] H. Yoshida, Y. Tomiyama, J. Ishikawa et al., "Integrin-associated protein/CD47 regulates motile activity in human B-cell lines through CDC42," Blood, vol. 96, no. 1, pp. 234-241, 2000.

[21] J. Koenigsknecht and G. Landreth, "Microglial phagocytosis of fibrillar $\beta$-amyloid through a $\beta 1$ integrin-dependent mechanism," Journal of Neuroscience, vol. 24, no. 44, pp. 9838-9846, 2004.

[22] M. Orazizadeh, H. S. Lee, B. Groenendijk et al., "CD47 associates with alpha 5 integrin and regulates responses of human articular chondrocytes to mechanical stimulation in an in vitro model," Arthritis Research \& Therapy, vol. 10, no. 1, article R4, 2008.

[23] J. C. Adams and J. Lawler, "The thrombospondins," International Journal of Biochemistry and Cell Biology, vol. 36, no. 6, pp. 961-968, 2004.

[24] A. G. Gao, F. P. Lindberg, J. M. Dimitry, E. J. Brown, and W. A. Frazier, "Thrombospondin modulates $\alpha_{\mathrm{V}} \beta_{3}$ function through integrin-associated protein," Journal of Cell Biology, vol. 135, no. 2, pp. 533-544, 1996. 
[25] W. A. Frazier, A. G. Gao, J. Dimitry et al., “The thrombospondin receptor integrin-associated protein (CD47) functionally couples to heterotrimeric $\mathrm{G}_{i}$," Journal of Biological Chemistry, vol. 274, no. 13, pp. 8554-8560, 1999.

[26] J. S. Isenberg, F. Hyodo, L. K. Pappan et al., "Blocking thrombospondin-1/CD47 signaling alleviates deleterious effects of aging on tissue responses to ischemia," Arteriosclerosis, Thrombosis, and Vascular Biology, vol. 27, no. 12, pp. 2582-2588, 2007.

[27] J. S. Isenberg, M. J. Romeo, C. Yu et al., “Thrombospondin-1 stimulates platelet aggregation by blocking the antithrombotic activity of nitric oxide/cGMP signaling," Blood, vol. 111, no. 2, pp. 613-623, 2008.

[28] S. D. Blystone, F. P. Lindberg, S. E. LaFlamme, and E. J. Brown, "Integrin $\beta_{3}$ cytoplasmic tail is necessary and sufficient for regulation of $\alpha_{5} \beta_{1}$ phagocytosis by $\alpha_{\mathrm{V}} \beta_{3}$ and integrinassociated protein," Journal of Cell Biology, vol. 130, no. 3, pp. 745-754, 1995.

[29] R. A. Rebres, L. E. Vaz, J. M. Green, and E. J. Brown, "Normal ligand binding and signaling by CD47 (Integrin-associated protein) requires a long range disulfide bond between the extracellular and membrane-spanning domains," Journal of Biological Chemistry, vol. 276, no. 37, pp. 34607-34616, 2001.

[30] J. F. McDonald, A. Zheleznyak, and W. A. Frazier, "Cholesterolindependent interactions with CD47 enhance $\alpha_{\mathrm{V}} \beta_{3}$ avidity," Journal of Biological Chemistry, vol. 279, no. 17, pp. 17301-17311, 2004.

[31] M. A. Schwartz, E. J. Brown, and B. Fazeli, "A 50-kDa integrinassociated protein is required for integrin-regulated calcium entry in endothelial cells," Journal of Biological Chemistry, vol. 268, no. 27, pp. 19931-19934, 1993.

[32] T. A. Shahan, A. Fawzi, G. Bellon, J. C. Monboisse, and N. A. Kefalides, "Regulation of tumor cell chemotaxis by type IV collagen is mediated by a $\mathrm{Ca}^{2+}$-dependent mechanism requiring CD47 and the integrin $\alpha_{\mathrm{V}} \beta_{3}$," Journal of Biological Chemistry, vol. 275, no. 7, pp. 4796-4802, 2000.

[33] R. A. Rebres, J. M. Green, M. I. Reinhold, M. Ticchioni, and E. J. Brown, "Membrane raft association of CD47 is necessary for actin polymerization and protein kinase $\mathrm{C} \theta$ translocation in its synergistic activation of T cells," Journal of Biological Chemistry, vol. 276, no. 10, pp. 7672-7680, 2001.

[34] M. Waclavicek, O. Majdic, T. Stulnig et al., "T cell stimulation via CD47: agonistic and antagonistic effects of CD47 monoclonal antibody 1/1A4," Journal of Immunology, vol. 159, no. 11, pp. 5345-5354, 1997.

[35] A. L. Wu, J. Wang, A. Zheleznyak, and E. J. Brownt, "Ubiquitinrelated proteins regulate interaction of vimentin intermediate filaments with the plasma membrane," Molecular Cell, vol. 4, no. 4, pp. 619-625, 1999.

[36] M. Miyashita, H. Ohnishi, H. Okazawa et al., "Promotion of neurite and filopodium formation by CD47: roles of integrins, rac, and Cdc42," Molecular Biology of the Cell, vol. 15, no. 8, pp. 3950-3963, 2004.

[37] T. Murata, H. Ohnishi, H. Okazawa et al., "CD47 promotes neuronal development through Src- and FRG/Vav2-mediated activation of Rac and Cdc42," Journal of Neuroscience, vol. 26, no. 48, pp. 12397-12407, 2006.

[38] O. J. Broom, Y. Zhang, P. A. Oldenborg, R. Massoumi, and A. Sjölander, "CD47 regulates collagen I-induced cyclooxygenase2 expression and intestinal epithelial cell migration," PLOS ONE, vol. 4, no. 7, Article ID e6371, 2009.
[39] W. Chuang and C. F. Lagenaur, "Central nervous system antigen P84 can serve as a substrate for neurite outgrowth," Developmental Biology, vol. 137, no. 2, pp. 219-232, 1990.

[40] S. Comu, W. Weng, S. Olinsky et al., "The murine P84 neural adhesion molecule is SHPS-1, a member of the phosphatasebinding protein family," Journal of Neuroscience, vol. 17, no. 22, pp. 8702-8710, 1997.

[41] Y. Fujioka, T. Matozaki, T. Noguchi et al., "A novel membrane glycoprotein, SHPS-1, that binds the SH2-domain- containing protein tyrosine phosphatase SHP-2 in response to mitogens and cell adhesion," Molecular and Cellular Biology, vol. 16, no. 12, pp. 6887-6899, 1996.

[42] A. Kharitonenkov, Z. Chen, I. Sures, H. Wang, J. Schilling, and A. Ullrich, "A family of proteins that inhibit signalling through tyrosine kinase receptors," Nature, vol. 386, no. 6621, pp. 181186, 1997.

[43] C. Saginario, H. Sterling, C. Beckers et al., "MFR, a putative receptor mediating the fusion of macrophages," Molecular and Cellular Biology, vol. 18, no. 11, pp. 6213-6223, 1998.

[44] S. I. Sano, H. Ohnishi, A. Omori, J. Hasegawa, and M. Kubota, "BIT, an immune antigen receptor-like molecule in the brain," FEBS Letters, vol. 411, no. 2-3, pp. 327-334, 1997.

[45] A. Veillette, E. Thibaudeaut, and S. Latour, "High expression of inhibitory receptor SHPS-1 and its association with proteintyrosine phosphatase SHP-1 in macrophages," Journal of Biological Chemistry, vol. 273, no. 35, pp. 22719-22728, 1998.

[46] J. F. Timms, K. D. Swanson, A. Marie-Gardine et al., "SHPS-1 is a scaffold for assembling distinct adhesion-regulated multiprotein complexes in macrophages," Current Biology, vol. 9, no. 16, pp. 927-930, 1999.

[47] M. Seiffert, P. Brossart, C. Cant et al., "Signal-regulatory protein $\alpha(\operatorname{SIRP} \alpha)$ but not $\operatorname{SIRP} \beta$ is involved in T-cell activation, binds to CD47 with high affinity, and is expressed on immature $\mathrm{CD} 34^{+} \mathrm{CD} 38^{-}$hematopoietic cells," Blood, vol. 97, no. 9, pp. 2741-2749, 2001.

[48] Y. Ichigotani, S. Matsuda, K. Machida et al., "Molecular cloning of a novel human gene (SIRP-B2) which encodes a new member of the SIRP/SHPS-1 protein family," Journal of Human Genetics, vol. 45, no. 6, pp. 378-382, 2000.

[49] J. Dietrich, M. Cella, M. Seiffert, H. J. Bühring, and M. Colonna, "Cutting edge: signal-regulatory protein $\beta 1$ is a DAP12associated activating receptor expressed in myeloid cells," Journal of Immunology, vol. 164, no. 1, pp. 9-12, 2000.

[50] E. Tomasello, C. Cant, H. J. Buhring et al., "Association of signalregulatory proteins $\beta$ with KARAP/DAP-12," European Journal of Immunology, vol. 30, pp. 2147-2156, 2000.

[51] A. N. Barclay and M. H. Brown, "The SIRP family of receptors and immune regulation," Nature Reviews Immunology, vol. 6, no. 6, pp. 457-464, 2006.

[52] P. Jiang, C. F. Lagenaur, and V. Narayanan, "Integrin-associated protein is a ligand for the P84 neural adhesion molecule," Journal of Biological Chemistry, vol. 274, no. 2, pp.559-562, 1999.

[53] M. Seiffert, C. Cant, Z. Chen et al., "Human signal-regulatory protein is expressed on normal, but not on subsets of leukemic myeloid cells and mediates cellular adhesion involving its counterreceptor CD47," Blood, vol. 94, no. 11, pp. 3633-3643, 1999.

[54] G. Brooke, J. D. Holbrook, M. H. Brown, and A. N. Barclay, "Human lymphocytes interact directly with CD47 through a novel member of the signal regulatory protein (SIRP) family," Journal of Immunology, vol. 173, no. 4, pp. 2562-2570, 2004. 
[55] L. Piccio, W. Vermi, K. S. Boles et al., "Adhesion of human T cells to antigen-presenting cells through SIRP $\beta 2-C D 47$ interaction costimulates T-cell proliferation," Blood, vol. 105, no. 6, pp. 24212427, 2005.

[56] N. Legrand, N. D. Huntington, M. Nagasawa et al., "Functional CD47/signal regulatory protein alpha (SIRP $\alpha)$ interaction is required for optimal human T- and natural killer- (NK) cell homeostasis in vivo," Proceedings of the National Academy of Sciences of the United States of America, vol. 108, pp. 1322413229, 2011.

[57] M. Sato-Hashimoto, Y. Saito, H. Ohnishi et al., "Signal regulatory protein $\alpha$ regulates the homeostasis of Tlymphocytes in the spleen," The Journal of Immunology, vol. 187, pp. 291-297, 2011.

[58] S. Latour, H. Tanaka, C. Demeure et al., "Bidirectional negative regulation of human $\mathrm{T}$ and dendritic cells by CD47 and its cognate receptor signal-regulator protein- $\alpha$ : down-regulation of IL-12 responsiveness and inhibition of dendritic cell activation," Journal of Immunology, vol. 167, no. 5, pp. 2547-2554, 2001.

[59] S. Hagnerud, P. P. Manna, M. Cella et al., "Deficit of CD47 results in a defect of marginal zone dendritic cells, blunted immune response to particulate antigen and impairment of skin dendritic cell migration," Journal of Immunology, vol. 176, no. 10, pp. 5772-5778, 2006.

[60] Y. Saito, H. Iwamura, T. Kaneko et al., "Regulation by SIRP $\alpha$ of dendritic cell homeostasis in lymphoid tissues," Blood, vol. 116, no. 18, pp. 3517-3525, 2010.

[61] V. Q. Van, S. Lesage, S. Bouguermouh et al., "Expression of the self-marker CD47 on dendritic cells governs their trafficking to secondary lymphoid organs," EMBO Journal, vol. 25, no. 23, pp. 5560-5568, 2006.

[62] H. E. De Vries, J. J. A. Hendriks, H. Honing et al., "Signalregulatory protein $\alpha$-CD47 interactions are required for the transmigration of monocytes across cerebral endothelium," Journal of Immunology, vol. 168, no. 11, pp. 5832-5839, 2002.

[63] Y. Liu, H. J. Bühring, K. Zen et al., "Signal regulatory protein (SIRP $\alpha$ ), a cellular ligand for CD47, regulates neutrophil transmigration," Journal of Biological Chemistry, vol. 277, no. 12, pp. 10028-10036, 2002.

[64] A. N. Barclay, "Signal regulatory protein alpha (SIRP $\alpha$ )/CD47 interaction and function," Current Opinion in Immunology, vol. 21, no. 1, pp. 47-52, 2009.

[65] T. Matozaki, Y. Murata, H. Okazawa, and H. Ohnishi, "Functions and molecular mechanisms of the CD47-SIRP $\alpha$ signalling pathway," Trends in Cell Biology, vol. 19, no. 2, pp. 72-80, 2009.

[66] P. Lundberg, C. Koskinen, P. A. Baldock et al., "Osteoclast formation is strongly reduced both in vivo and in vitro in the absence of CD47/SIRP $\alpha$-interaction," Biochemical and Biophysical Research Communications, vol. 352, no. 2, pp. 444-448, 2007.

[67] L. A. Maile, V. E. DeMambro, C. Wai et al., "An essential role for the association of CD47 to SHPS-1 in skeletal remodeling," Journal of Bone and Mineral Research, vol. 26, no. 9, pp. 20682081, 2011.

[68] P. A. Oldenborg, A. Zheleznyak, Y. F. Fang, C. F. Lagenaur, H. D. Gresham, and F. P. Lindberg, "Role of CD47 as a marker of self on red blood cells," Science, vol. 288, no. 5473, pp. 2051-2054, 2000.

[69] S. Subramanian, R. Parthasarathy, S. Sen, E. T. Boder, and D. E. Discher, "Species- and cell type-specific interactions between CD47 and human SIRP $\alpha$," Blood, vol. 107, no. 6, pp. 2548-2556, 2006.
[70] S. Subramanian, E. T. Boder, and D. E. Discher, "Phylogenetic divergence in human SIRPalpha-CD47 interactions reveals locus of species-specificity: implications for the binding site," Journal of Biological Chemistry, vol. 282, no. 3, pp. 1805-1818, 2007.

[71] T. Ogura, T. Noguchi, R. Murai-Takebe, T. Hosooka, N. Honma, and M. Kasuga, "Resistance of B16 melanoma cells to CD47induced negative regulation of motility as a result of aberrant $N$-glycosylation of SHPS-1," Journal of Biological Chemistry, vol. 279, no. 14, pp. 13711-13720, 2004.

[72] V. Mateo, L. Lagneaux, D. Bron et al., "CD47 ligation induces caspase-independent cell death in chronic lymphocytic leukemia," Nature Medicine, vol. 5, no. 11, pp. 1277-1284, 1999.

[73] R. D. Pettersen, K. Hestdal, M. K. Olafsen, S. O. Lie, and F. P. Lindberg, "CD47 signals T cell death," Journal of Immunology, vol. 162, no. 12, pp. 7031-7040, 1999.

[74] P. P. Manna and W. A. Frazier, "The mechanism of CD47dependent killing of $\mathrm{T}$ cells: heterotrimeric Gi-dependent inhibition of protein kinase A," Journal of Immunology, vol. 170, no. 7, pp. 3544-3553, 2003.

[75] P. P. Manna and W. A. Frazier, "CD47 mediates killing of breast tumor cells via Gi-dependent inhibition of protein kinase A," Cancer Research, vol. 64, no. 3, pp. 1026-1036, 2004.

[76] S. Uno, Y. Kinoshita, Y. Azuma et al., "Antitumor activity of a monoclonal antibody against CD47 in xenograft models of human leukemia," Oncology Reports, vol. 17, no. 5, pp. 1189-1194, 2007.

[77] V. Mateo, E. J. Brown, G. Biron et al., "Mechanisms of CD47-induced caspase-independent cell death in normal and leukemic cells: link between phosphatidylserine exposure and cytoskeleton organization," Blood, vol. 100, no. 8, pp. 2882-2890, 2002.

[78] L. Lamy, M. Ticchioni, A. K. Rouquette-Jazdanian et al., "CD47 and the $19 \mathrm{kDA}$ interacting protein-3 (BNIP3) in T cell apoptosis," Journal of Biological Chemistry, vol. 278, no. 26, pp. 23915-23921, 2003.

[79] L. Lamy, A. Foussat, E. J. Brown, P. Bornstein, M. Ticchioni, and A. Bernard, "Interactions between CD47 and thrombospondin reduce inflammation," Journal of Immunology, vol. 178, no. 9, pp. 5930-5939, 2007.

[80] M. P. Blundell, A. Worth, G. Bouma, and A. J. Thrasher, "The Wiskott-Aldrich syndrome: the actin cytoskeleton and immune cell function," Disease Markers, vol. 29, no. 3-4, pp. 157-175, 2010.

[81] G. Roué, N. Bitton, V. J. Yuste et al., "Mitochondrial dysfunction in CD47-mediated caspase-independent cell death: ros production in the absence of cytochrome c and AIF release," Biochimie, vol. 85, no. 8, pp. 741-746, 2003.

[82] M. Sagawa, T. Shimizu, N. Fukushima et al., "A new disulfidelinked dimer of a single-chain antibody fragment against human CD47 induces apoptosis in lymphoid malignant cells via the hypoxia inducible factor-1 $\alpha$ pathway," Cancer Science, vol. 102, no. 6, pp. 1208-1215, 2011.

[83] P. P. Manna, J. Dimitry, P. A. Oldenborg, and W. A. Frazier, "CD47 augments fas/CD95-mediated apoptosis," Journal of Biological Chemistry, vol. 280, no. 33, pp. 29637-29644, 2005.

[84] Y. Kikuchi, S. Uno, Y. Yoshimura et al., "A bivalent single-chain Fv fragment against CD47 induces apoptosis for leukemic cells," Biochemical and Biophysical Research Communications, vol. 315, no. 4, pp. 912-918, 2004.

[85] Y. Kikuchi, S. Uno, Y. Kinoshita et al., "Apoptosis inducing bivalent single-chain antibody fragments against CD47 showed 
antitumor potency for multiple myeloma," Leukemia Research, vol. 29, no. 4, pp. 445-450, 2005.

[86] U. Johansson, K. Higginbottom, and M. Londei, “CD47 ligation induces a rapid caspase-independent apoptosis-like cell death in human monocytes and dendritic cells," Scandinavian Journal of Immunology, vol. 59, no. 1, pp. 40-49, 2004.

[87] H. Koshimizu, T. Araki, S. Takai et al., "Expression of CD47/ integrin-associated protein induces death of cultured cerebral cortical neurons," Journal of Neurochemistry, vol. 82, no. 2, pp. 249-257, 2002.

[88] M. A. Freyberg, D. Kaiser, R. Graf, P. Vischer, and P. Friedl, "Integrin-associated protein and thrombospondin-1 as endothelial mechanosensitive death mediators," Biochemical and Biophysical Research Communications, vol. 271, no. 3, pp. 584$588,2000$.

[89] M. A. Freyberg, D. Kaiser, R. Graf, J. Buttenbender, and P. Friedl, "Proatherogenic flow conditions initiate endothelial apoptosis via thrombospondin-1 and the integrin-associated protein," Biochemical and Biophysical Research Communications, vol. 286, no. 1, pp. 141-149, 2001.

[90] R. Graf, M. Freyberg, D. Kaiser, and P. Friedl, "Mechanosensitive induction of apoptosis in fibroblasts is regulated by thrombospondin-1 and integrin associated protein (CD47)," Apoptosis, vol. 7, no. 6, pp. 493-498, 2002.

[91] A. Saumet, M. B. Slimane, M. Lanotte, J. Lawler, and V. Dubernard, "Type 3 repeat/C-terminal domain of thrombospondin-1 triggers caspase-independent cell death through CD $47 / \alpha_{v} \beta_{3}$ in promyelocytic leukemia NB4 cells," Blood, vol. 106 , no. 2, pp. 658-667, 2005.

[92] G. M. Rath, C. Schneider, S. Dedieu et al., “Thrombospondin1 C-terminal-derived peptide protects thyroid cells from ceramide-induced apoptosis through the adenylyl cyclase pathway," International Journal of Biochemistry and Cell Biology, vol. 38, no. 12, pp. 2219-2228, 2006.

[93] G. M. Rath, C. Schneider, S. Dedieu et al., "The C-terminal CD47/IAP-binding domain of thrombospondin-1 prevents camptothecin- and doxorubicin-induced apoptosis in human thyroid carcinoma cells," Biochimica et Biophysica Acta, vol. 1763, no. 10, pp. 1125-1134, 2006.

[94] G. D. Grossfeld, D. A. Ginsberg, J. P. Stein et al., "Thrombospondin-1 expression in bladder cancer: association with p53 alterations, tumor angiogenesis, and tumor progression," Journal of the National Cancer Institute, vol. 89, no. 3, pp. 219227, 1997.

[95] I. Sargiannidou, J. Zhou, and G. P. Tuszynski, "The role of thrombospondin-1 in tumor progression," Experimental Biology and Medicine, vol. 226, no. 8, pp. 726-733, 2001.

[96] C. D. Sutton, K. O’Byrne, J. C. Goddard et al., "Expression of thrombospondin-1 in resected colorectal liver metastases predicts poor prognosis," Clinical Cancer Research, vol. 11, no. 18, pp. 6567-6573, 2005.

[97] N. Avent, P. A. Judson, S. F. Parsons et al., "Monoclonal antibodies that recognize different membrane proteins that are deficient in $\mathrm{Rh}_{\text {null }}$ human erythrocytes. One group of antibodies reacts with a variety of cells and tissues whereas the other group is erythroid-specific," Biochemical Journal, vol. 251, no. 2, pp. 499-505, 1988.

[98] J. P. Cartron, " $R H$ blood group system and molecular basis of Rh-deficiency," Best Practice \& Research Clinical Haematology, vol. 12, no. 4, pp. 655-689, 1999.

[99] A. C. Rybicki, R. S. Schwartz, E. J. Hustedt, and C. E. Cobb, "Increased rotational mobility and extractability of band 3 from protein 4.2-deficient erythrocyte membranes: evidence of a role for protein 4.2 in strengthening the band 3-cytoskeleton linkage," Blood, vol. 88, no. 7, pp. 2745-2753, 1996.

[100] M. J. A. Tanner, "Band 3 anion exchanger and its involvement in erythrocyte and kidney disorders," Current Opinion in Hematology, vol. 9, no. 2, pp. 133-139, 2002.

[101] L. J. Bruce, R. Beckmann, M. L. Ribeiro et al., "A band 3-based macrocomplex of integral and peripheral proteins in the RBC membrane," Blood, vol. 101, no. 10, pp. 4180-4188, 2003.

[102] P. B. Booth, S. Serjeantson, D. G. Woodfield, and D. Amato, "Selective depression of blood group antigens associated with hereditary ovalocytosis among Melanesians," Vox Sanguinis, vol. 32, no. 2, pp. 99-110, 1977.

[103] L. J. Bruce, S. Ghosh, M. J. King et al., "Absence of CD47 in protein 4.2-deficient hereditary spherocytosis in man: an interaction between the Rh complex and the band 3 complex," Blood, vol. 100, no. 5, pp. 1878-1885, 2002.

[104] K. N. Dahl, C. M. Westhoff, and D. E. Discher, "Fractional attachment of CD47 (IAP) to the erythrocyte cytoskeleton and visual colocalization with Rh protein complexes," Blood, vol. 101, no. 3, pp. 1194-1199, 2003.

[105] I. Mouro-Chanteloup, M. Johansen, E. J. Brown, and J. P. C. Y. Cartron, "Normal red cell membrane expression of Rh and RhAG polypeptides in CD47-deficient mice," Vox Sanguinis, vol. 78, article P030, 2000.

[106] I. Mouro-Chanteloup, J. Delaunay, P. Gane et al., "Evidence that the red cell skeleton protein 4.2 interacts with the Rh membrane complex member CD47," Blood, vol. 101, no. 1, pp. 338-344, 2003.

[107] A. M. Anniss and R. L. Sparrow, "Expression of CD47 (integrinassociated protein) decreases on red blood cells during storage," Transfusion and Apheresis Science, vol. 27, no. 3, pp. 233-238, 2002.

[108] N. Kamel, F. Goubran, N. Ramsis, and A. S. Ahmed, "Effects of storage time and leucocyte burden of packed and buffy-coat depleted red blood cell units on red cell storage lesion," Blood Transfusion, vol. 8, no. 4, pp. 260-266, 2010.

[109] A. Stewart, S. Urbaniak, M. Turner, and H. Bessos, "The application of a new quantitative assay for the monitoring of integrin-associated protein CD47 on red blood cells during storage and comparison with the expression of CD47 and phosphatidylserine with flow cytometry," Transfusion, vol. 45, no. 9, pp. 1496-1503, 2005.

[110] C. R. Gilson, T. S. Kraus, E. A. Hod et al., "A novel mouse model of red blood cell storage and posttransfusion in vivo survival," Transfusion, vol. 49, no. 8, pp. 1546-1553, 2009.

[111] P. Burger, P. Hilarius-Stokman, D. de Korte, T. K. van den Berg, and R. van Bruggen, "CD47 functions as a molecular switch for erythrocyte phagocytosis," Blood, vol. 119, pp. 5512-5521, 2012.

[112] J. L. Holovati, K. A. Wong, J. M. Webster, and J. P. Acker, "The effects of cryopreservation on red blood cell microvesiculation, phosphatidylserine externalization, and CD47 expression," Transfusion, vol. 48, no. 8, pp. 1658-1668, 2008.

[113] O. Rubin, G. Canelli, J. Delobel, N. Lion, and J. D. Tissot, "Red blood cell microparticles: clinical relevance," Transfusion Medicine and Hemotherapy, vol. 39, pp. 342-347, 2012.

[114] A. G. Kriebardis, M. H. Antonelou, K. E. Stamoulis, E. Economou-Petersen, L. H. Margaritis, and I. S. Papassideri, "RBC-derived vesicles during storage: ultrastructure, protein composition, oxidation, and signaling components," Transfusion, vol. 48, no. 9, pp. 1943-1953, 2008. 
[115] L. Fossati-Jimack, S. Azeredo Da Silveira, T. Moll et al., "Selective increase of autoimmune epitope expression on aged erythrocytes in mice: implications in anti-erythrocyte autoimmune responses," Journal of Autoimmunity, vol. 18, no. 1, pp. 17-25, 2002.

[116] R. K. Saxena, N. Bhardwaj, S. Sachar, N. Puri, and S. Khandelwal, "A double in vivo biotinylation technique for objective assessment of aging and clearance of mouse erythrocytes in blood circulation," Transfusion Medicine and Hemotherapy, vol. 39, pp. 335-341, 2012.

[117] S. Khandelwal, N. Van Rooijen, and R. K. Saxena, "Reduced expression of CD47 during murine red blood cell (RBC) senescence and its role in RBC clearance from the circulation," Transfusion, vol. 47, no. 9, pp. 1725-1732, 2007.

[118] S. K. Ballas and N. Mohandas, "Pathophysiology of vasoocclusion," Hematology/Oncology Clinics of North America, vol. 10, no. 6, pp. 1221-1239, 1996.

[119] S. K. Ballas and N. Mohandas, "Sickle red cell microrheology and sickle blood rheology," Microcirculation, vol. 11, no. 2, pp. 209-225, 2004

[120] J. E. Brittain, K. J. Mlinar, C. S. Anderson, E. P. Orringer, and L. V. Parise, "Integrin-associated protein is an adhesion receptor on sickle red blood cells for immobilized thrombospondin," Blood, vol. 97, no. 7, pp. 2159-2164, 2001.

[121] J. E. Brittain, K. J. Mlinar, C. S. Anderson, E. P. Orringer, and L. V. Parise, "Activation of sickle red blood cell adhesion via integrin-associated protein/CD47-induced signal transduction," Journal of Clinical Investigation, vol. 107, no. 12, pp. 15551562, 2001.

[122] G. A. Grabowski, "Phenotype, diagnosis, and treatment of Gaucher's disease," The Lancet, vol. 372, no. 9645, pp. 1263-1271, 2008.

[123] D. Bratosin, J. P. Tissier, H. Lapillonne et al., "A cytometric study of the red blood cells in gaucher disease reveals their abnormal shape that may be involved in increased erythrophagocytosis," Cytometry Part B, vol. 80, no. 1, pp. 28-37, 2011.

[124] H. Jiang and L. Chess, "How the immune system achieves selfnonself discrimination during adaptive immunity," Advances in Immunology, vol. 102, pp. 95-133, 2009.

[125] C. A. Janeway and R. Medzhitov, "Innate immune recognition," Annual Review of Immunology, vol. 20, pp. 197-216, 2002.

[126] P. F. Zipfel and C. Skerka, "Complement regulators and inhibitory proteins," Nature Reviews Immunology, vol. 9, no. 10, pp. 729-740, 2009.

[127] K. Kärre, H. G. Ljunggren, G. Piontek, and R. Kiessling, "Selective rejection of $\mathrm{H}$-2-deficient lymphoma variants suggests alternative immune defence strategy," Nature, vol. 319, no. 6055, pp. 675-678, 1986.

[128] L. L. Lanier, "NK cell recognition," Annual Review of Immunology, vol. 23, pp. 225-274, 2004.

[129] V. Kumar and M. E. McNerney, "A new self: MHC-class-Iindependent natural-killer-cell self-tolerance," Nature Reviews Immunology, vol. 5, no. 5, pp. 363-374, 2005.

[130] T. A. M. Steevels and L. Meyaard, "Immune inhibitory receptors: essential regulators of phagocyte function," European Journal of Immunology, vol. 41, no. 3, pp. 575-587, 2011.

[131] J. V. Ravetch and L. L. Lanier, "Immune inhibitory receptors," Science, vol. 290, no. 5489, pp. 84-89, 2000.

[132] H. Liénard, P. Bruhns, O. Malbec, W. H. Fridman, and M. Daëron, "Signal regulatory proteins negatively regulate immunoreceptor-dependent cell activation," Journal of Biological Chemistry, vol. 274, no. 45, pp. 32493-32499, 1999.
[133] N. K. Tonks and B. G. Neel, "From form to function: signaling by protein tyrosine phosphatases," Cell, vol. 87 , no. 3, pp. 365368, 1996.

[134] B. R. Blazar, F. P. Lindberg, E. Ingulli et al., "CD47 (Integrinassociated Protein) engagement of dendritic cell and macrophage counterreceptors is required to prevent the clearance of donor lymphohematopoietic cells," Journal of Experimental Medicine, vol. 194, no. 4, pp. 541-549, 2001.

[135] J. W. Goodman and L. H. Smith, "Erythrocyte life span in normal mice and in radiation bone marrow chimeras," American Journal of Physiology, vol. 200, pp. 764-770, 1961.

[136] J. Horky, J. Vacha, and V. Znojil, "Comparison of life span of erythrocytes in some inbred strains of mouse using 14C-labelled glycine," Physiologia Bohemoslovaca, vol. 27, no. 3, pp. 209-217, 1978.

[137] N. Van Rooijen and A. Sanders, "Liposome mediated depletion of macropbages: mechanism of action, preparation of liposomes and applications," Journal of Immunological Methods, vol. 174, no. 1-2, pp. 83-93, 1994.

[138] T. Ishikawa-Sekigami, Y. Kaneko, H. Okazawa et al., "SHPS1 promotes the survival of circulating erythrocytes through inhibition of phagocytosis by splenic macrophages," Blood, vol. 107, no. 1, pp. 341-348, 2006.

[139] M. Olsson, P. Bruhns, W. A. Frazier, J. V. Ravetch, and P. A. Oldenborg, "Platelet homeostasis is regulated by platelet expression of CD47 under normal conditions and in passive immune thrombocytopenia," Blood, vol. 105, no. 9, pp. 35773582,2005

[140] T. Yamao, T. Noguchi, U. Takeuchi et al., "Negative regulation of platelet clearance and of the macrophage phagocytic response by the transmembrane glycoprotein SHPS-1," Journal of Biological Chemistry, vol. 277, no. 42, pp. 39833-39839, 2002.

[141] S. J. Gardai, K. A. McPhillips, S. C. Frasch et al., "Cell-surface calreticulin initiates clearance of viable or apoptotic cells through trans-activation of LRP on the phagocyte," Cell, vol.123, no. 2, pp. 321-334, 2005.

[142] A. Nilsson, L. Vesterlund, and P. A. Oldenborg, "Macrophage expression of LRP1, a receptor for apoptotic cells and unopsonized erythrocytes, can be regulated by glucocorticoids," Biochemical and Biophysical Research Communications, vol. 417, no. 4, pp. 1304-1309, 2012.

[143] A. Nilsson and P. A. Oldenborg, "CD47 promotes both phosphatidylserine-independent and phosphatidylserine-dependent phagocytosis of apoptotic murine thymocytes by nonactivated macrophages," Biochemical and Biophysical Research Communications, vol. 387, no. 1, pp. 58-63, 2009.

[144] H. Okazawa, S. I. Motegi, N. Ohyama et al., "Negative regulation of phagocytosis in macrophages by the CD47-SHPS-1 system," Journal of Immunology, vol. 174, no. 4, pp. 2004-2011, 2005.

[145] P. A. Oldenborg, H. D. Gresham, and F. P. Lindberg, "CD47signal regulatory protein $\alpha(\operatorname{SIRP} \alpha)$ regulates $\mathrm{Fc} \gamma$ and complement receptor-mediated phagocytosis," Journal of Experimental Medicine, vol. 193, no. 7, pp. 855-861, 2001.

[146] P. A. Oldenborg, H. D. Gresham, Y. Chen, S. Izui, and F. P. Lindberg, "Lethal autoimmune hemolytic anemia in CD47deficient nonobese diabetic (NOD) mice," Blood, vol. 99, no. 10, pp. 3500-3504, 2002.

[147] M. Kozlowski, I. Mlinaric-Rascan, G. S. Feng, R. Shen, T. Pawson, and K. A. Siminovitch, "Expression and catalytic activity of the tyrosine phosphatase PTP1C is severely impaired in motheaten and viable motheaten mice," Journal of Experimental Medicine, vol. 178, no. 6, pp. 2157-2163, 1993. 
[148] L. D. Schultz, D. R. Coman, C. L. Bailey et al., “"Viable motheaten", a new allele at the motheaten locus. I. Pathology," American Journal of Pathology, vol. 116, no. 2, pp. 179-192, 1984.

[149] L. D. Shultz, P. A. Schweitzer, T. V. Rajan et al., "Mutations at the murine motheaten locus are within the hematopoietic cell protein-tyrosine phosphatase $(H c p h)$ gene," Cell, vol. 73, no. 7 , pp. 1445-1454, 1993.

[150] M. Olsson, A. Nilsson, and P. A. Oldenborg, "Dose-dependent inhibitory effect of CD47 in macrophage uptake of IgGopsonized murine erythrocytes," Biochemical and Biophysical Research Communications, vol. 352, no. 1, pp. 193-197, 2007.

[151] M. Gitik, S. Liraz-Zaltsman, P. A. Oldenborg, F. Reichert, and S. Rotshenker, "Myelin down-regulates myelin phagocytosis by microglia and macrophages through interactions between CD47 on myelin and SIRP $\alpha$ (signal regulatory protein- $\alpha$ ) on phagocytes," Journal of Neuroinflammation, vol. 8, article 24, 2011.

[152] G. E. Janka, "Hemophagocytic syndromes," Blood Reviews, vol. 21, no. 5, pp. 245-253, 2007.

[153] T. Kuriyama, K. Takenaka, K. Kohno et al., "Engulfment of hematopoietic stem cells caused by down-regulation of CD47 is critical in the pathogenesis of hemophagocytic lymphohistiocytosis," Blood, vol. 120, no. 19, pp. 4058-4067, 2012.

[154] M. Olsson and P. A. Oldenborg, "CD47 on experimentally senescent murine RBCs inhibits phagocytosis following $\mathrm{Fc} \gamma$ receptor-mediated but not scavenger receptor-mediated recognition by macrophages," Blood, vol. 112, no. 10, pp. 4259-4267, 2008.

[155] R. K. Tsai and D. E. Discher, "Inhibition of "self" engulfment through deactivation of myosin-II at the phagocytic synapse between human cells," Journal of Cell Biology, vol. 180, no. 5, pp. 989-1003, 2008.

[156] A. H. Jonsson and W. M. Yokoyama, "Natural killer cell tolerance: licensing and other mechanisms," Advances in Immunology, vol. 101, pp. 27-79, 2009.

[157] H. Wang, M. L. Madariaga, S. Wang, N. Van Rooijen, P. A. Oldenborg, and Y. G. Yang, "Lack of CD47 on nonhematopoietic cells induces split macrophage tolerance to CD47null cells," Proceedings of the National Academy of Sciences of the United States of America, vol. 104, no. 34, pp. 13744-13749, 2007.

[158] Y. G. Yang, "CD47 in xenograft rejection and tolerance induction: review article," Xenotransplantation, vol. 17, no. 4, pp. 267273,2010

[159] M. R. Elliott and K. S. Ravichandran, "Clearance of apoptotic cells: implications in health and disease," Journal of Cell Biology, vol. 189, no. 7, pp. 1059-1070, 2010.

[160] S. J. Gardai, D. L. Bratton, C. A. Ogden, and P. M. Henson, "Recognition ligands on apoptotic cells: a perspective," Journal of Leukocyte Biology, vol. 79, no. 5, pp. 896-903, 2006.

[161] K. S. Ravichandran and U. Lorenz, "Engulfment of apoptotic cells: signals for a good meal," Nature Reviews Immunology, vol. 7, no. 12, pp. 964-974, 2007.

[162] K. S. Ravichandran, "Beginnings of a good apoptotic meal: the find-me and eat-me signaling pathways," Immunity, vol. 35, no. 4, pp. 445-455, 2011.

[163] R. Hanayama and S. Nagata, "Impaired involution of mammary glands in the absence of milk fat globule EGF factor 8," Proceedings of the National Academy of Sciences of the United States of America, vol. 102, no. 46, pp. 16886-16891, 2005.

[164] M. Sandahl, D. M. Hunter, K. E. Strunk, H. S. Earp, and R. S. Cook, "Epithelial cell-directed efferocytosis in the post-partum mammary gland is necessary for tissue homeostasis and future lactation," BMC Developmental Biology, vol. 10, article 122, 2010.

[165] K. Tada, M. Tanaka, R. Hanayama et al., "Tethering of apoptotic cells to phagocytes through binding of CD47 to src homology 2 domain-bearing protein tyrosine phosphatase substrate-1," Journal of Immunology, vol. 171, no. 11, pp. 5718-5726, 2003.

[166] C. A. Ogden, A. DeCathelineau, P. R. Hoffmann et al., "Clq and mannose binding lectin engagement of cell surface calreticulin and CD91 initiates macropinocytosis and uptake of apoptotic cells," Journal of Experimental Medicine, vol. 194, no. 6, pp. 781795, 2001.

[167] R. W. Vandivier, C. A. Ogden, V. A. Fadok et al., "Role of surfactant proteins $\mathrm{A}, \mathrm{D}$, and $\mathrm{Clq}$ in the clearance of apoptotic cells in vivo and in vitro: calreticulin and CD91 as a common collectin receptor complex," Journal of Immunology, vol. 169, no. 7, pp. 3978-3986, 2002.

[168] M. Löwenberg, C. Stahn, D. W. Hommes, and F. Buttgereit, "Novel insights into mechanisms of glucocorticoid action and the development of new glucocorticoid receptor ligands," Steroids, vol. 73, no. 9-10, pp. 1025-1029, 2008.

[169] R. P. Schleimer, "An overview of glucocorticoid anti-inflammatory actions," European Journal of Clinical Pharmacology, vol. 45, no. 1, pp. S3-S7, 1993.

[170] K. M. Giles, K. Ross, A. G. Rossi, N. A. Hotchin, C. Haslett, and I. Dransfield, "Glucocorticoid augmentation of macrophage capacity for phagocytosis of apoptotic cells is associated with reduced p130Cas expression, loss of paxillin/pyk2 phosphorylation, and high levels of active rac," Journal of Immunology, vol. 167, no. 2, supplement 1, pp. 976-986, 2001.

[171] Y. Liu, J. M. Cousin, J. Hughes et al., "Glucocorticoids promote nonphlogistic phagocytosis of apoptotic leukocytes," Journal of Immunology, vol. 162, no. 6, pp. 3639-3646, 1999.

[172] S. Jaiswal, C. H. M. Jamieson, W. W. Pang et al., "CD47 is upregulated on circulating hematopoietic stem cells and leukemia cells to avoid phagocytosis," Cell, vol. 138, no. 2, pp. 271-285, 2009.

[173] R. Majeti, M. P. Chao, A. A. Alizadeh et al., "CD47 is an adverse prognostic factor and therapeutic antibody target on human acute myeloid leukemia stem cells," Cell, vol. 138, no. 2, pp. 286299, 2009.

[174] S. B. Willingham, J. P. Volkmer, A. J. Gentles et al., "The CD47-signal regulatory protein alpha (SIRPa) interaction is a therapeutic target for human solid tumors," Proceedings of the National Academy of Sciences of the United States of America, vol. 109, pp. 6662-6667, 2012.

[175] A. P. A. Theocharides, L. Jin, P. Y. Cheng et al., "Disruption of SIRP $\alpha$ signaling in macrophages eliminates human acute myeloid leukemia stem cells in xenografts," The Journal of Experimental Medicine, vol. 209, no. 10, pp. 1883-1899, 2012.

[176] M. P. Chao, A. A. Alizadeh, C. Tang et al., "Anti-CD47 antibody synergizes with rituximab to promote phagocytosis and eradicate non-hodgkin lymphoma," Cell, vol. 142, no. 5, pp. 699$713,2010$.

[177] X. W. Zhao, E. M. van Beek, K. Schornagel et al., "CD47-signal regulatory protein- $\alpha(\operatorname{SIRP} \alpha)$ interactions form a barrier for antibody-mediated tumor cell destruction," Proceedings of the National Academy of Sciences of the United States of America, vol. 108, pp. 18342-118347, 2011.

[178] Y. G. Yang and M. Sykes, "Xenotransplantation: current status and a perspective on the future," Nature Reviews Immunology, vol. 7, no. 7, pp. 519-531, 2007. 
[179] A. Karlsson-Parra, A. Ridderstad, A. C. Wallgren, E. Möller, H. G. Ljunggren, and O. Korsgren, "Xenograft rejection of porcine islet-like cell clusters in normal and natural killer cell-depleted mice," Transplantation, vol. 61, no. 9, pp. 1313-1320, 1996.

[180] G. Wu, O. Korsgren, J. Zhang, Z. Song, N. Van Rooijen, and A. Tibell, "Pig islet xenograft rejection is markedly delayed in macrophage-depleted mice: a study in streptozotocin diabetic animals," Xenotransplantation, vol. 7, no. 3, pp. 214-220, 2000.

[181] M. Abe, J. Cheng, J. Qi et al., "Elimination of porcine hemopoietic cells by macrophages in mice," Journal of Immunology, vol. 168, no. 2, pp. 621-628, 2002.

[182] H. Wang, J. Verhalen, M. L. Madariaga et al., "Attenuation of phagocytosis of xenogeneic cells by manipulating CD47," Blood, vol. 109, no. 2, pp. 836-842, 2007.

[183] K. Ide, H. Wang, H. Tahara et al., "Role for CD47-SIRP $\alpha$ signaling in xenograft rejection by macrophages," Proceedings of the National Academy of Sciences of the United States of America, vol. 104, no. 12, pp. 5062-5066, 2007.

[184] X. Han, H. Sterling, Y. Chen et al., "CD47, a ligand for the macrophage fusion receptor, participates in macrophage multinucleation," Journal of Biological Chemistry, vol. 275, no. 48, pp. 37984-37992, 2000.

[185] Ö. Uluçkan, S. N. Becker, H. Deng et al., "CD47 regulates bone mass and tumor metastasis to bone," Cancer Research, vol. 69, no. 7, pp. 3196-3204, 2009.

[186] E. M. Van Beek, T. J. De Vries, L. Mulder et al., "Inhibitory regulation of osteoclast bone resorption by signal regulatory protein $\alpha$, FASEB Journal, vol. 23, no. 12, pp. 4081-4090, 2009.

[187] A. Vignery, "Osteoclasts and giant cells: macrophage-macrophage fusion mechanism," International Journal of Experimental Pathology, vol. 81, no. 5, pp. 291-304, 2000. 


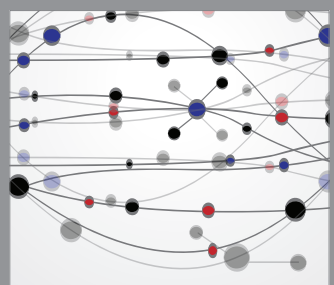

The Scientific World Journal
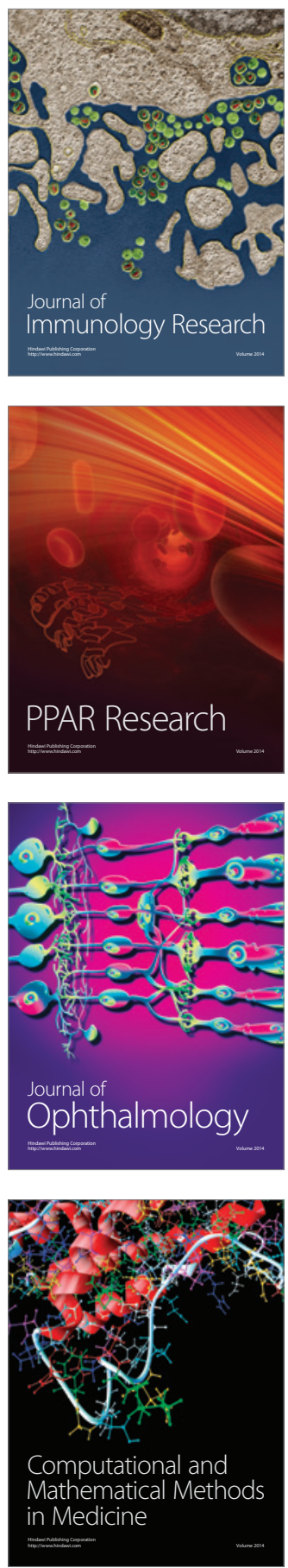

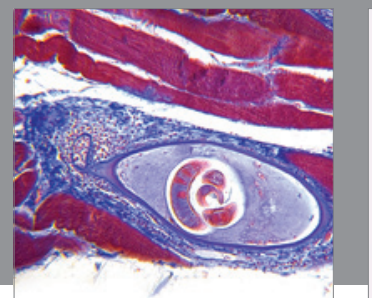

Gastroenterology

Research and Practice
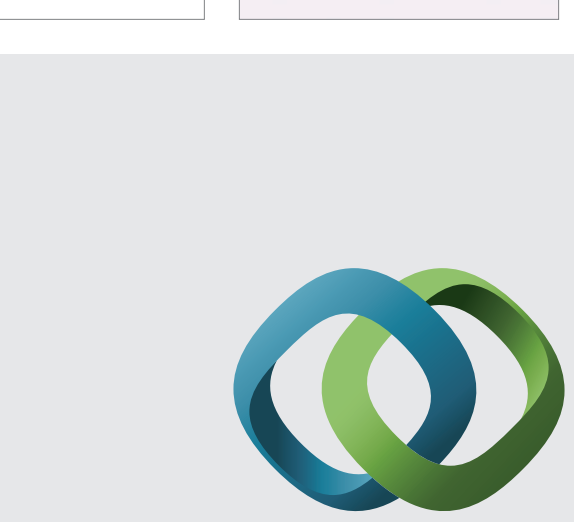

\section{Hindawi}

Submit your manuscripts at

http://www.hindawi.com
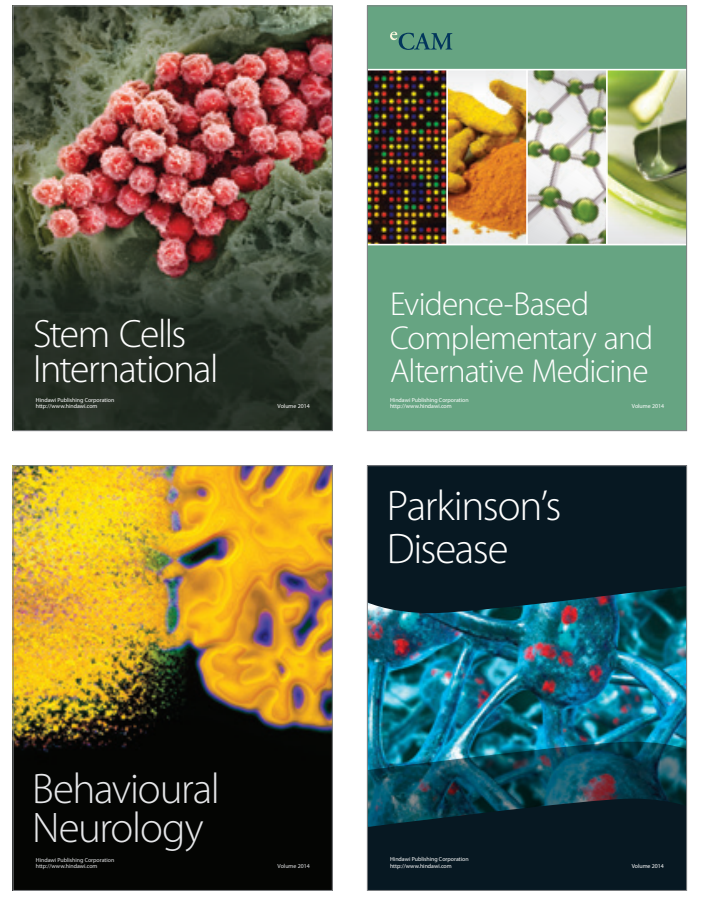
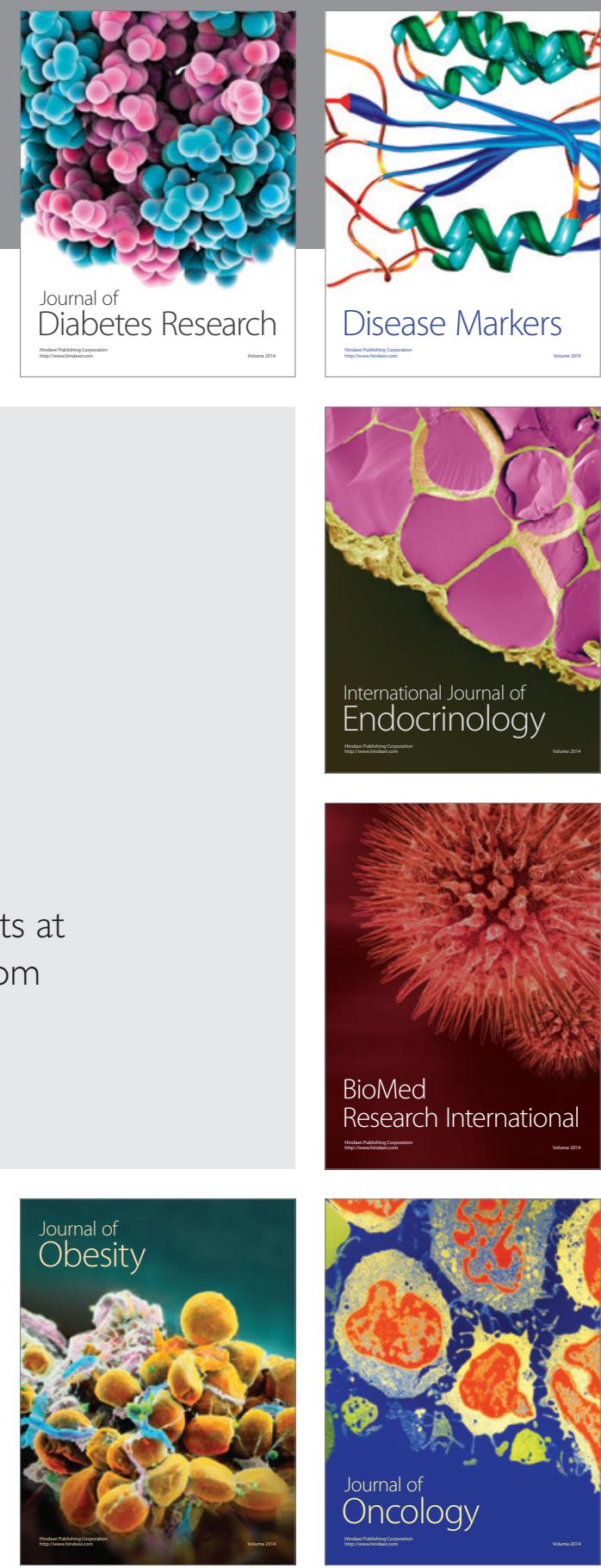

Disease Markers
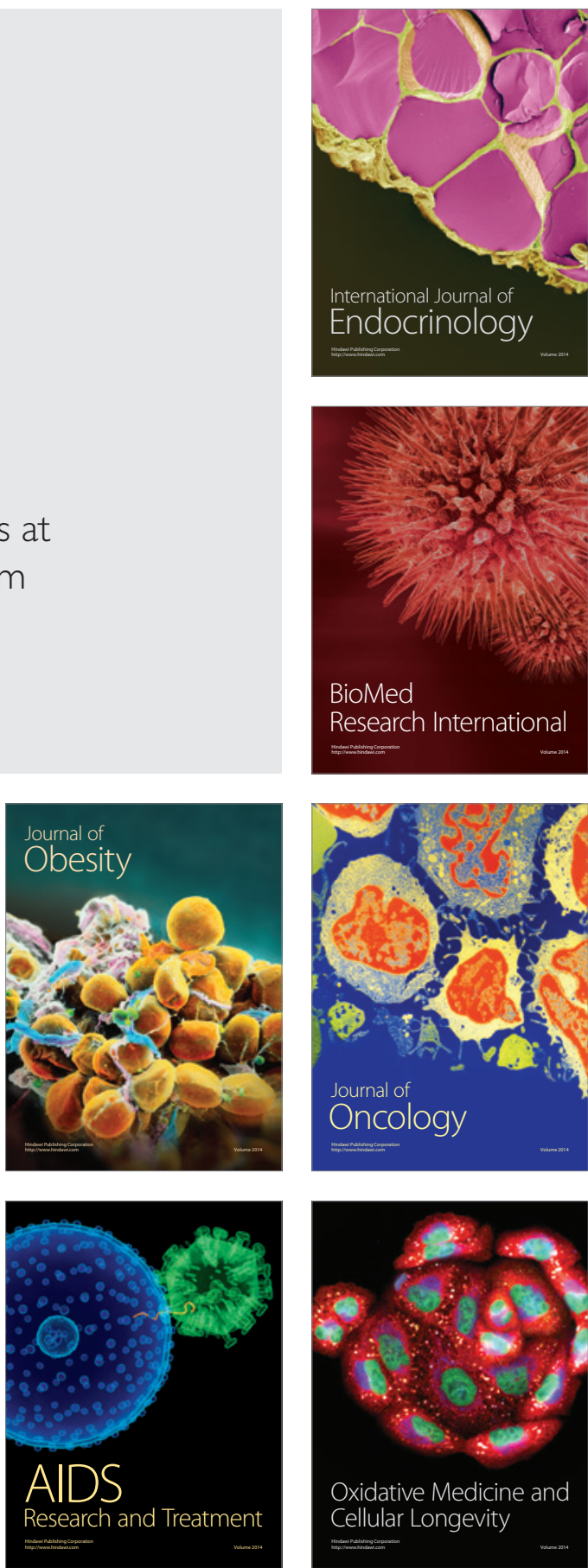